\title{
Polymorphism in Griseofulvin: New Story of an Old Drug with Polyethylene Glycol
}

Xiao Ou, * Shuting Li, * Yunyun Chen, Haowei Rong, Ao Li, Ming Lu*

ABSTRACT Griseofulvin (GSF) is an antifungal drug that has been clinically used for six decades. Here, we present a rich polymorphism of GSF crystallizing from GSF dispersions with polyethylene glycol (PEG), including five true polymorphs (Forms I-V) and one inclusion complex (IC). Two new polymorphs were reported for the first time, denoted Forms IV and V. Singlecrystal structures of new polymorphs and a GSF-PEG IC were determined by X-ray crystallography using single crystals cultivated by microdroplet melt crystallization. A comprehensive solid form landscape of GSF is established to describe phase conversions between polymorphs. Enhancement in molecular mobility by PEG is suggested to be the reason for the nucleation of two new polymorphs, while the small geographic radius of PEG is attributed to the formation of a GSF-PEG IC increasing the density and lowering the Gibbs free energy of the system. This work expands our understanding of the complicated crystallization behavior of GSF in dispersions with PEG and emphasizes the importance of polymorphism control during the manufacturing and storage of PEG-based solid dispersions to achieve reproducible and consistent pharmaceutical performance. The results also suggest that polymer addition is an alternative strategy that cannot be neglected in polymorphism screening.

KEYWORDS Griseofelvin, polyethylene glycol, dispersion, polymorphism, inclusion complex 


\section{Introduction}

The emergence of a large number of poorly soluble drugs emphasizes the importance of solubility and dissolution enhancement. Polyethylene glycol (PEG)-based semicrystalline solid dispersions are an effective way to solve this problem, and commercial products have been marketed, such as GRIS-PEG ${ }^{\circledR}$ approved by the U.S. Food and Drug Administration (FDA) and bifendate pills approved by the Chinese FDA. However, the reproducibility and consistency of solid dispersion is difficult to control, which might result in variations in bioavailability and efficacy. Although the phase behavior of PEG-based solid dispersions has been investigated, ${ }^{1-10}$ the crystallization of drugs in dispersions with PEG during manufacturing and storage is still poorly understood.

Griseofulvin (GSF, Figure 1) is an antifungal natural product first isolated from Penicillium griseofulvum in 1939 by Oxford, Raistrick and Simonart. ${ }^{11}$ Its biological activity was first reported by Brian ${ }^{12}$ in 1949. A commercial GSF formulation for the treatment of ringworm was launched in 1962 in the U.S. by Wyeth Ayerst under the trade name GRISACTIN ${ }^{\circledR} .{ }^{13}$ To date, GSF has been in clinical use in animals and humans for more than six decades.
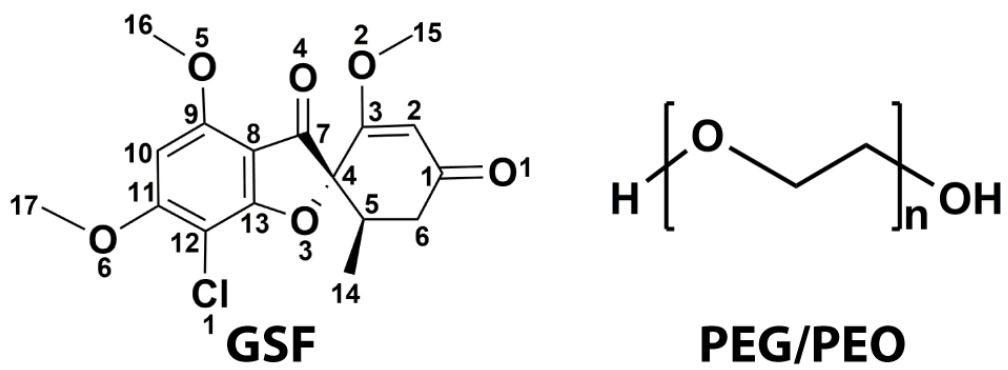

\section{PEG/PEO}

Figure 1. Molecular structures of GSF and PEG/PEO.

GSF is poorly water soluble, and its oral bioavailability is significantly influenced by particle size (Atkinson, 1962). ${ }^{14}$ PEG, a GRAS (generally recognized as safe) pharmaceutical polymer, is 
a key recipient in commercial formulations of GSF. The story of GSF and PEG began in 1969 when Chiou et al. ${ }^{15}$ reported that the formation of a GSF solid dispersion with PEG can highly improve the dissolution ${ }^{15}$ and bioavailability ${ }^{16}$ of GSF. Since 1975 , GRIS-PEG ${ }^{\circledR}$, a PEG-based GSF solid dispersion, has been approved by the U.S. FDA. ${ }^{17}$ In this novel formulation, GSF exists as ultramicro-sized crystals in the PEG matrix to improve dissolution. To prepare this formulation, GSF and PEG were comelted at $200{ }^{\circ} \mathrm{C}$ and then quenched to $40{ }^{\circ} \mathrm{C}$ for aging, during which GSF and PEG recrystallize. ${ }^{15}$ The influence of PEG on GSF crystallization behaviors has attracted attention. In 2014, GSF was reported to cocrystallize with $\mathrm{PEG}^{18}$, and this GSF-PEG crystalline inclusion complex (IC) could improve both the dissolution rate and solubility of GSF ${ }^{19}$. In 2017 , polyethylene oxide (PEO), the isomer of PEG, differing only in molecular weight and polymerization method, was reported to remarkably accelerate the growth of amorphous GSF crystals, partially due to the increase in global molecular mobility. ${ }^{20}$

GSF is a classic polymorphic compound. The first crystal structure of GSF (Form I, the most stable polymorph) was reported in $1977 .{ }^{21}$ Over the next few decades, this drug was considered to be monomorphic until 2013, when two polymorphs (Forms II and III) were revealed by melt crystallization. $^{22}$ The single-crystal structure of Form II was solved in 2018 with the aid of PEG for growth acceleration. ${ }^{23}$ A single crystal of Form III was successfully grown in our lab using the melt microdroplet strategy, resulting in structure elucidation by X-ray crystallography in $2020 .^{24}$

In this work, we reported the complicated polymorphic behaviors of GSF dispersions with PEG and established the comprehensive polymorphic landscape of GSF. In total, five GSF polymorphs and one GSF-PEG IC were observed, including two new polymorphs (designated Forms IV and V). This emphasizes the importance of solid-state studies for the manufacturing and storage of PEG-based solid dispersions. 


\section{Materials and methods}

Materials. GSF (purity $>99.5 \%$, Form I), PEG (molecular weight, $M_{\mathrm{w}}: 200-10,000 \mathrm{~g} / \mathrm{mol}$ ) and PEO ( $\left.M_{\mathrm{w}}: 100,000-1,000,000 \mathrm{~g} / \mathrm{mol}\right)$ were purchased from Aladdin (Shanghai, China). Poly(1,4butylene adipate) $\left(\mathrm{PBA}, M_{\mathrm{w}}=12,000 \mathrm{~g} / \mathrm{mol}\right)$ and poly(ethylene succinate) $\left(\mathrm{PES}, M_{\mathrm{w}}=10,000\right.$ $\mathrm{g} / \mathrm{mol}$ ) were purchased from Aldrich (St. Louis, MO, USA). Poloxamer $188\left(M_{\mathrm{w}}=8,500 \mathrm{~g} / \mathrm{mol}\right)$, polyvinylpyrrolidone (PVP K30, $\left.M_{\mathrm{w}}=50,000 \mathrm{~g} / \mathrm{mol}\right)$, poly(1-vinylpyrrolidone-co-vinylacetate) (PVP VA64, $M_{\mathrm{w}}=45,000 \mathrm{~g} / \mathrm{mol}$ ), and PEG 6000-vinylcaprolactam-vinyl acetate grafted polymer (Soluplus, $M_{\mathrm{w}}=118,000 \mathrm{~g} / \mathrm{mol}$ ) were kindly supplied by BASF SE (Ludwigshafen, Germany). Hydroxy propyl methyl cellulose acetate succinate (HPMCAS HF) was kindly supplied by Ashland (Wilmington, DE, USA).

Differential scanning calorimetry (DSC). DSC thermograms were recorded on a Netzsch DSC 200-F3 calorimeter (Netzsch group, Germany). Samples of 1-5 mg were accurately weighed into perforated aluminum pans. DSC curves were recorded under a nitrogen atmosphere, and the temperature was increased from $30{ }^{\circ} \mathrm{C}$ to $240{ }^{\circ} \mathrm{C}$ at a heating rate of $10{ }^{\circ} \mathrm{C} / \mathrm{min}$ or $50{ }^{\circ} \mathrm{C} / \mathrm{min}$.

Powder X-ray diffraction (PXRD). PXRD patterns of GSF polymorphs were obtained using a Rigaku SmartLAB system (Rigaku, Japan) by $\mathrm{Cu} \mathrm{K} \alpha$ radiation with $\lambda=1.542 \AA$. The samples were placed on a monocrystalline silicon sample holder and scanned from $5^{\circ}$ to $40^{\circ}(2 \theta)$ at a speed of $6 \%$ min.

Raman microscopy. Raman spectra were collected using a confocal Raman microscope (InVia Qontor, Renishaw plc, Gloucestershire, UK) with a 50× objective and a $633 \mathrm{~nm}$ excitation wavelength to give a laser spot diameter of approximately $2 \mu \mathrm{m}$. Spectra were collected and analyzed using Renishaw WIRE 3.4 software. The wavelength scale was calibrated using silicon. Every spectrum was collected from at least three points of the sample. 
Synthesis and characterization of single crystals. Single crystals were synthesized by melt microdroplet method using a Linkam hot stage (THM S600, Waterfield, UK) combined with a Nikon microscope (Nikon Eclipse LV100N POL). Single-crystal X-ray diffraction (SCXRD) data were collected on an XtaLAB Synergy Dualflex HyPix diffractometer equipped with an Oxford Cryosystems low-temperature device with $\mathrm{Cu} \mathrm{K} \alpha$ radiation $(\lambda=1.54184 \AA)$. Cell refinement and data reduction were carried out by CrysAlisPro 1.171.39.46 (Rigaku OD, 2018). The crystal structure was solved by intrinsic phasing methods using SHELXT (Sheldrick, 2014) and refined by full-matrix least-squares using SHELXL (Sheldrick, 2016) in Olex 2-1.3 (Dolomanov et al., 2009). The simulated PXRD patterns and torsion angles were calculated using Mercury 2020.3.0.

\section{Results}

Discovery of new polymorphs. We first melted GSF-PEG 8000 physical mixtures at various drug loadings $(10 \%, 50 \%$ and $90 \%)$ at $230{ }^{\circ} \mathrm{C}$, quenched them at room temperature for $10 \mathrm{~min}$, and then aged them at different temperatures from $60{ }^{\circ} \mathrm{C}$ to $140{ }^{\circ} \mathrm{C}$. Once recrystallization finished, the final products were characterized by PXRD (shown in Figure 2). The results reveal plentiful polymorphic behaviors of GSF in dispersions with PEG 8000 upon aging, which are highly dependent on the drug loading and aging temperature. At 10\% drug loading, GSF slowly crystallized as Form I at $60{ }^{\circ} \mathrm{C}$ (Figure S1) and could not recrystallize completely in $24 \mathrm{~h}$ above $60{ }^{\circ} \mathrm{C}$ (data not shown). As the content of GSF increases to $50 \%$, the nucleation probability of Form I decreases to $70-80 \%$ upon annealing below $140{ }^{\circ} \mathrm{C}$; thus, other polymorphs have the opportunity to appear. As shown in Figure 2a, the GSF-PEG IC becomes the domain phase below $80^{\circ} \mathrm{C}$, for which the PXRD patterns are consistent with the previously reported pattern. Above $100^{\circ} \mathrm{C}$, some new diffraction peaks $\left(6.8^{\circ}, 10.3^{\circ}, 13.7^{\circ}, 17.1^{\circ}, 20.6^{\circ}\right.$ and $\left.27.6^{\circ}\right)$ appear, as shown by dotted lines. For the $90 \%$ GSF dispersions, these new peaks can also be observed in the PXRD 
patterns of the samples annealed above $80^{\circ} \mathrm{C}$ (Figure $2 \mathbf{b}$ ), accompanied by the specific peaks of the IC at $80{ }^{\circ} \mathrm{C}$ and Form III at $140{ }^{\circ} \mathrm{C}$. As the aging temperature decreases to $60{ }^{\circ} \mathrm{C}$, Form I becomes the domain phase. GSF has been reported to have three true polymorphs (I, II and III) and one GSF-PEG IC. The newly observed diffraction peaks are different from previously reported peaks (see dotted lines in Figure $\mathbf{2}$ a-b), indicating the formation of new GSF phases.
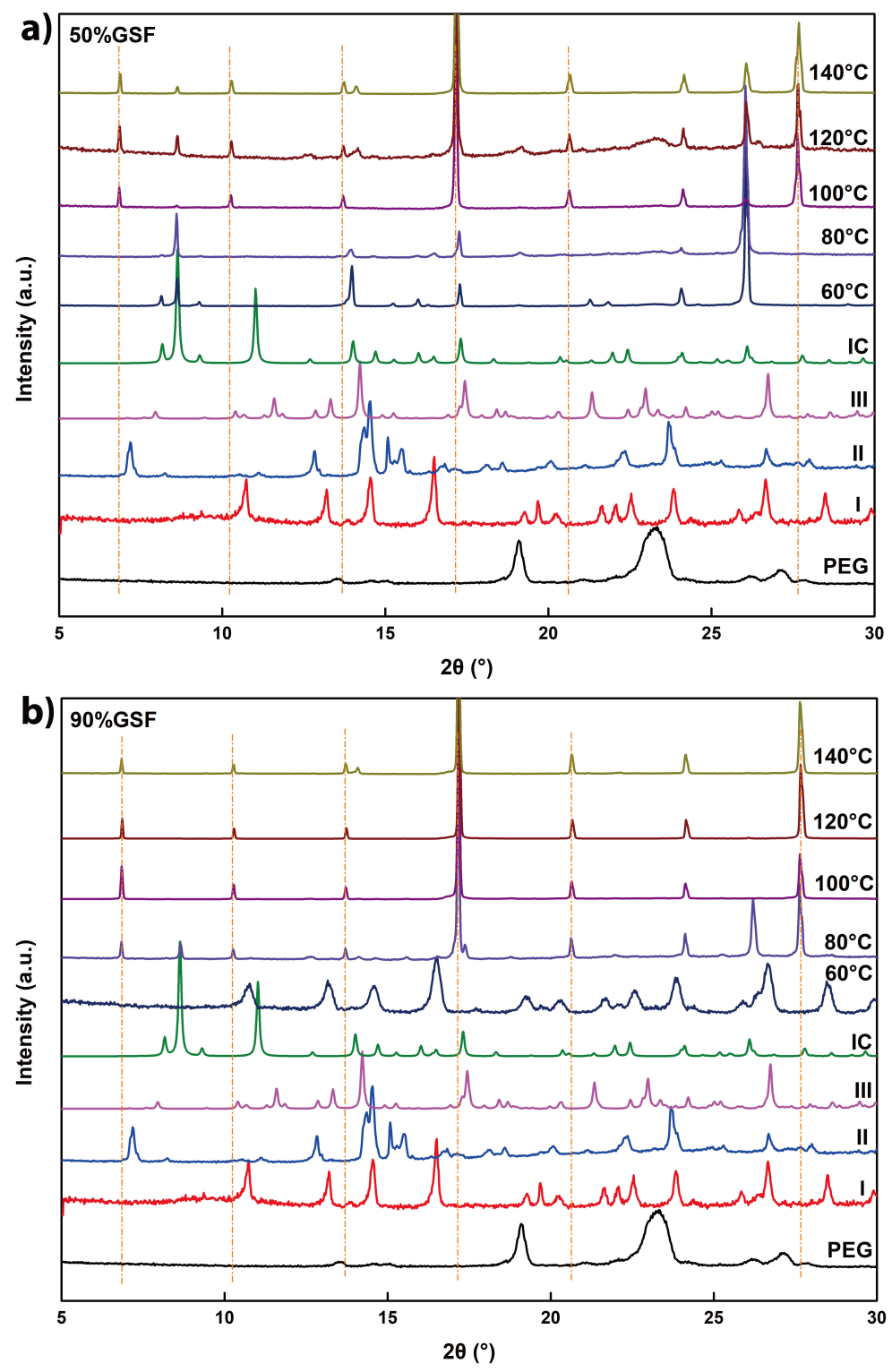

Figure 2. PXRD patterns of PEG 8000, Forms I-III, GSF-PEG 8000 IC and GSF-PEG 8000 dispersions upon aging at various temperatures until GSF completely crystallizes. 
We further investigated the two new phases. Four previously known solid forms of GSF have different melting points $\left(T_{\mathrm{m}} \mathrm{s}\right.$; Form I, $221^{\circ} \mathrm{C}$; Form II, $215^{\circ} \mathrm{C}$; Form III, $205^{\circ} \mathrm{C}$; GSF-PEG IC: $153{ }^{\circ} \mathrm{C}$ ). This makes it possible to identify different phases according to $T_{\mathrm{m}}$ by hot stage microscopy. We selected a 90\% GSF-PEG 8000 dispersion for further investigation because crystallization of PEG was inhibited at a drug loading of $90 \%$, which facilitates the investigation of GSF crystallization. We melted the physical mixture at $230^{\circ} \mathrm{C}$, quenched it at room temperature, and heated it at a very high rate of $150^{\circ} \mathrm{C} / \mathrm{min}$. As shown in Figure 3, GSF exhibited complicated phase behavior during the heating process. Some spherulites first nucleate spontaneously at approximately $80{ }^{\circ} \mathrm{C}$ (Figure 3a). This phase has a $T_{\mathrm{m}}$ of $190{ }^{\circ} \mathrm{C}$ (Figure 3c), which is different from the $T_{\mathrm{m}} \mathrm{s}$ of the four known solid forms, indicating a new phase. We denoted this phase Form $\mathrm{V}$ instead of Form IV. This is because another new phase with a higher $T_{\mathrm{m}}$ of $204{ }^{\circ} \mathrm{C}$ appears at the place where Form V melts through solid-solid phase conversion from Form $\mathrm{V}$ as spherulites and spontaneous nucleation as single crystals (Figure 3b-d). We designated the second new phase Form IV to keep the naming consistent, with the $T_{\mathrm{m}}$ order Form I $>$ Form II $>$ Form III $>$ Form IV $>$ Form V. The $T_{\mathrm{m}} \mathrm{S}$ of Forms IV $\left(204^{\circ} \mathrm{C}\right)$ and III $\left(205^{\circ} \mathrm{C}\right)$ are very similar, but their nucleation modes are quite different. Form III can nucleate spontaneously and independently, but Form IV cannot and usually forms as spherulites by solid-solid phase conversion from Form $\mathrm{V}$ or forms as single crystals from the place where Form $\mathrm{V}$ melts. We are not sure whether these single crystals nucleate spontaneously, but their nucleation seems to be related to Form V. After Form IV melts, we can observe Form II in the center of Form IV spherulites. In situ Raman microscopy proves that Form IV partially converts to Form II before melting (data not shown). 

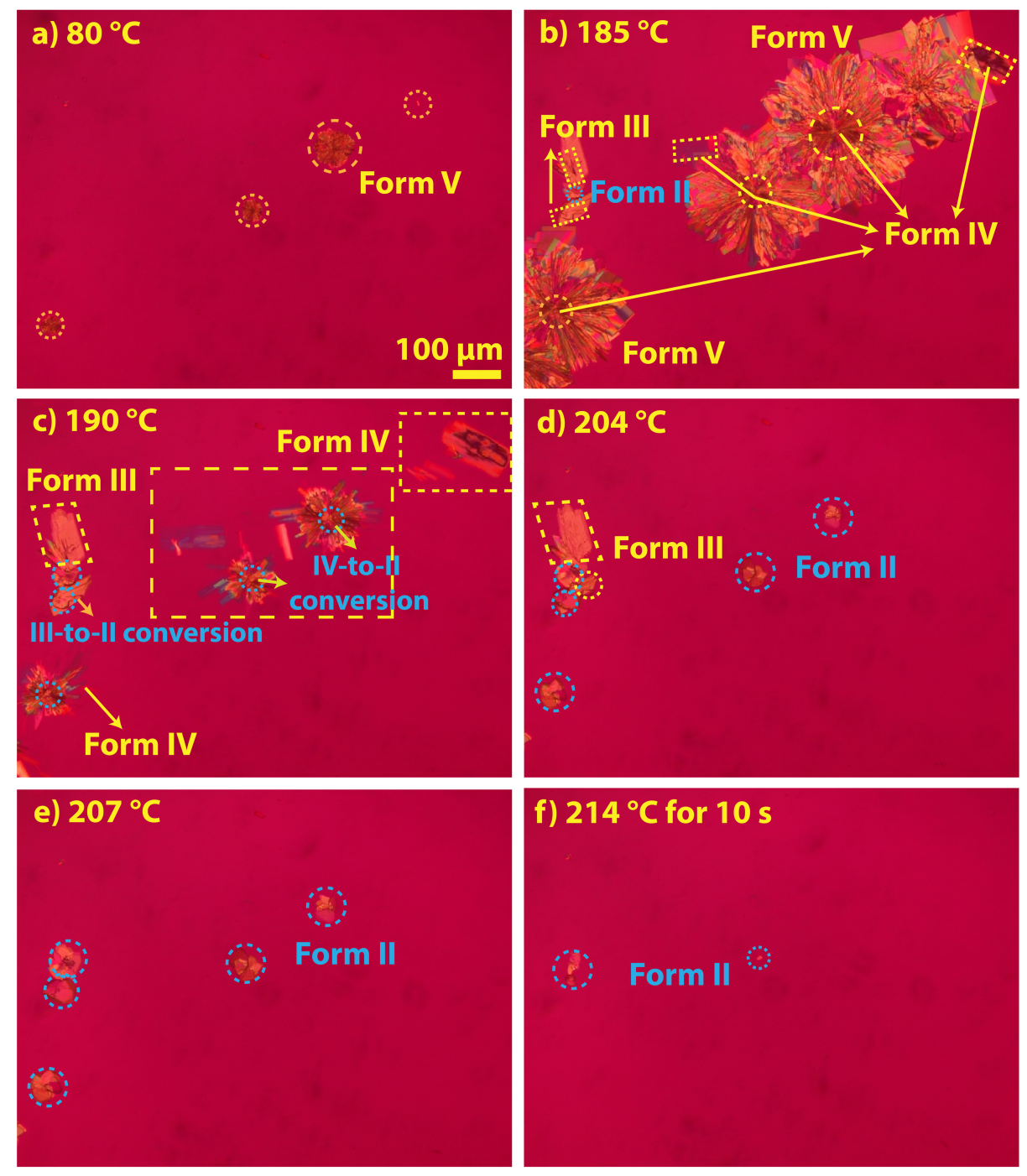

Figure 3. POM images of the phase behaviors of the $90 \%$ GSF dispersion with PEG 8000 at a heating rate of $150^{\circ} \mathrm{C} / \mathrm{min}$.

We further identified the new polymorphs using Raman microscopy. As shown in Figure 4a, Forms IV and V exhibit Raman spectra different from those of four known solid forms, further confirming that they are two new phases. Considering that GSF could form an IC with PEG ${ }^{18-19}$ and Forms IV and V were obtained from the GSF-PEG 8000 dispersion, it is necessary to confirm whether they are true polymorphs or ICs. This can be easily clarified by seeding Forms IV and V into neat GSF melts to see if they can grow and consume the materials because the GSF-PEG IC cannot grow in the absence of PEG. The results indicated that both phases can consume the GSF 
melt, yielding crystallographically pure samples. This verifies that they are true polymorphs of GSF and enables the acquisition of PXRD patterns and DSC curves. As shown in Figure $\mathbf{4 b}$, these two phases exhibit distinct PXRD patterns from those of the other three known polymorphs and IC, further confirming that they have different crystal structures. According to the PXRD data, the new peaks in Figure 2 are related to Form V, which is consistent with the experimental phenomenon where Form V can independently and spontaneously nucleate but Form IV cannot. The DSC data will be discussed in the thermodynamic stability and solid form landscape of the GSF polymorph section.
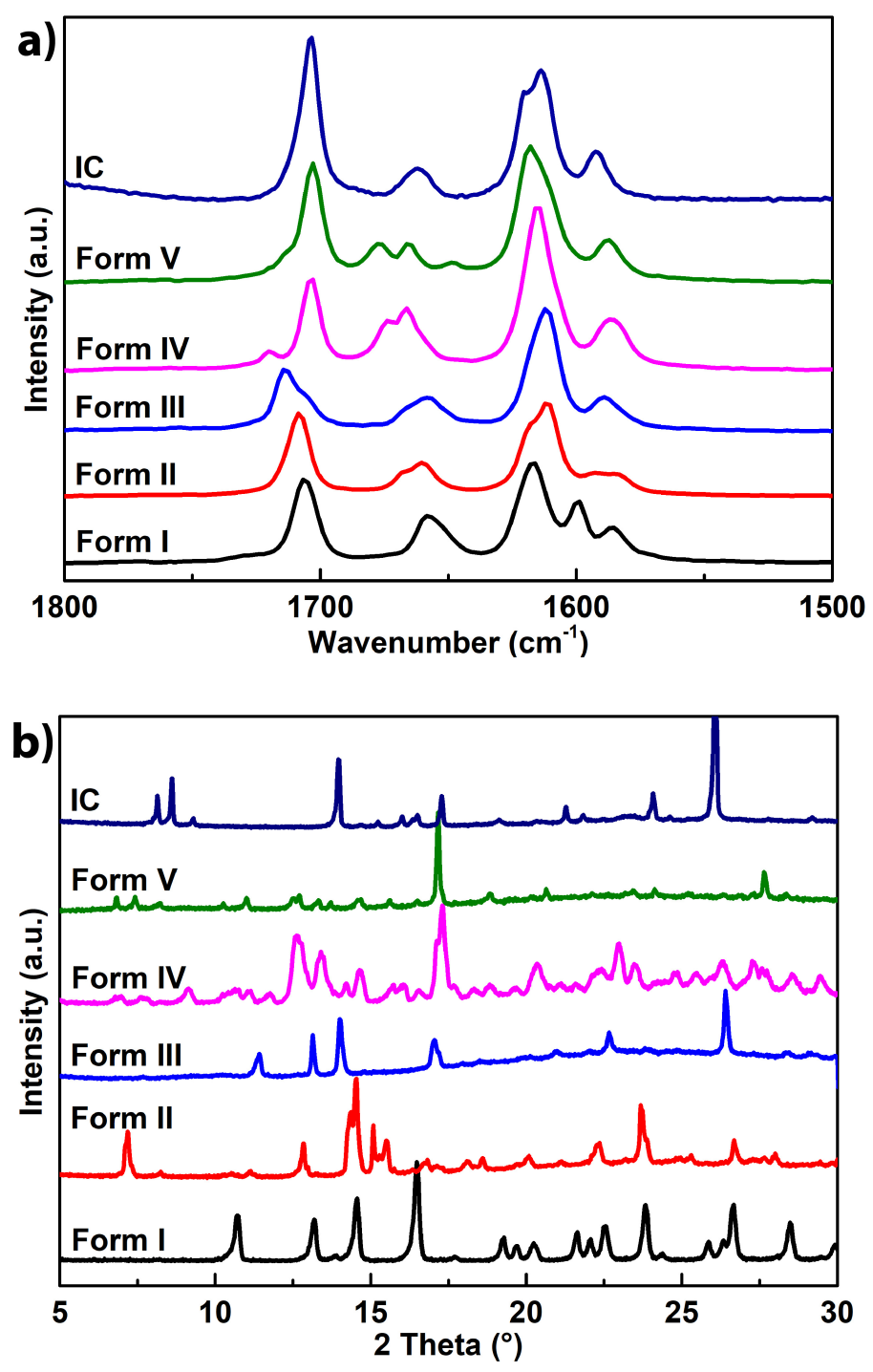


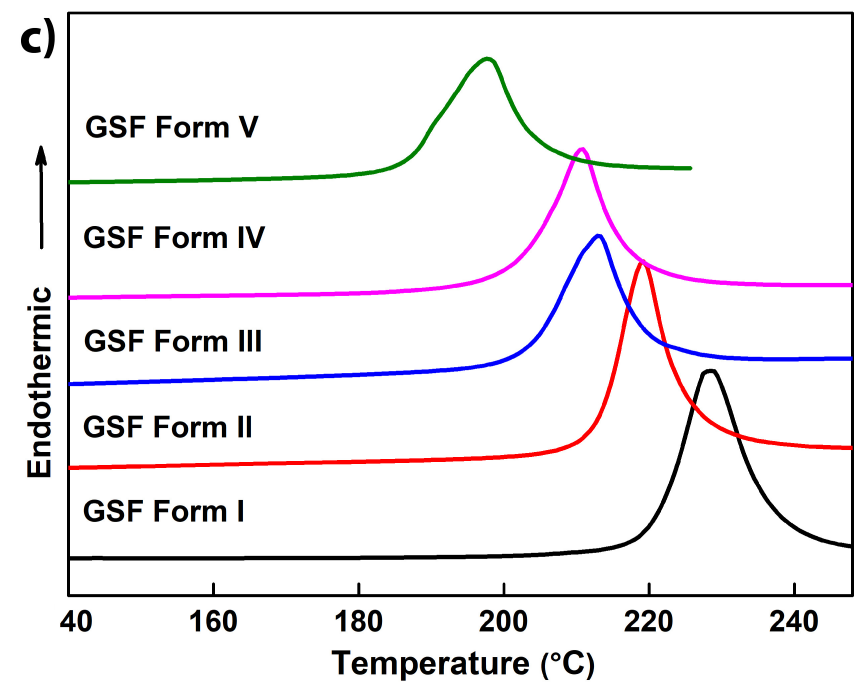

Figure 4. Raman spectra (a), PXRD patterns (b) and DSC curves (c) of GSF polymorphs. The heating rate in (c) is $50^{\circ} \mathrm{C} / \mathrm{min}$.

Single-crystal structure of Forms IV and V. Single-crystal structure is the gold standard for identifying a new crystal form. Therefore, we cultivated single crystals of Forms IV and V from melts using our newly developed melt microdroplet strategy ${ }^{24}$ for SCXRD data collection. The details are as follows. The corresponding polycrystalline seeds were introduced into pure GSF melt microdroplets at $185^{\circ} \mathrm{C}$ (for Form IV) and $180{ }^{\circ} \mathrm{C}$ (for Form V). A single-crystal seed was made for each case by partially melting the polycrystalline seeds and then harvesting into a single crystal with sufficient size and quality under appropriate conditions (Form IV: $195{ }^{\circ} \mathrm{C}$ for 25 min; Form $\mathrm{V}: 185^{\circ} \mathrm{C}$ for $15 \mathrm{~min}$ ) (Figure $5 \mathbf{a}$-b). The structures of the two polymorphs were successfully determined by SCXRD (Figure 5 and Table 1). The simulated PXRD patterns match the experimental patterns well (Figure S2), indicating that both structures are correct. Form IV crystallizes in an orthorhombic space group (space group $P 2{ }_{1} 2_{1} 2_{1}$ ), with $a=8.470 \AA, b=11.830$ $\AA, c=51.640 \AA, Z=12$, and Z' $=3$, while GSF Form V crystallizes in a monoclinic space group (space group $P 2_{1}$ ), with $a=8.443 \AA, b=11.871 \AA, c=25.728 \AA, \beta=90.18^{\circ}, Z=6$, and $Z^{\prime}=3$. Both new phases are confirmed to be true polymorphs of GSF. 
a)

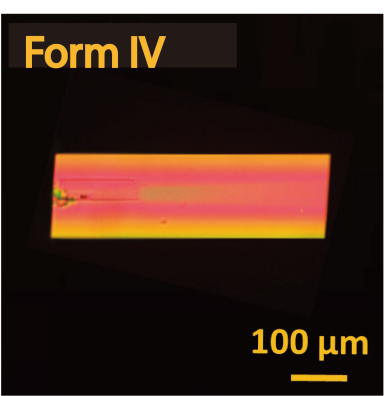

c)

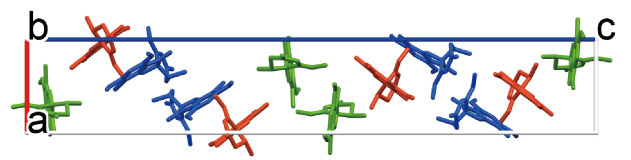

e)

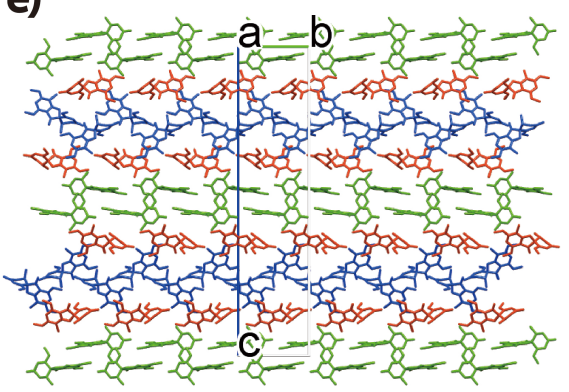

g)

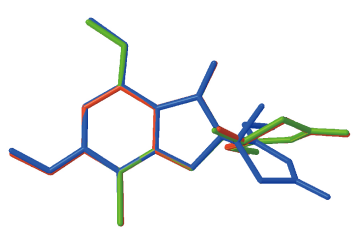

Form IV

f)

h) b)

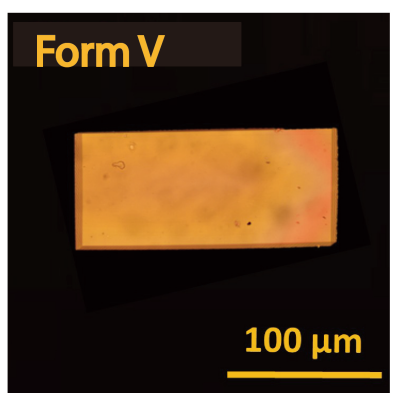

d)

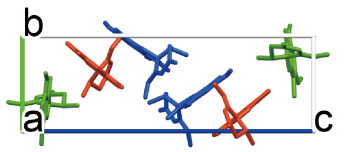

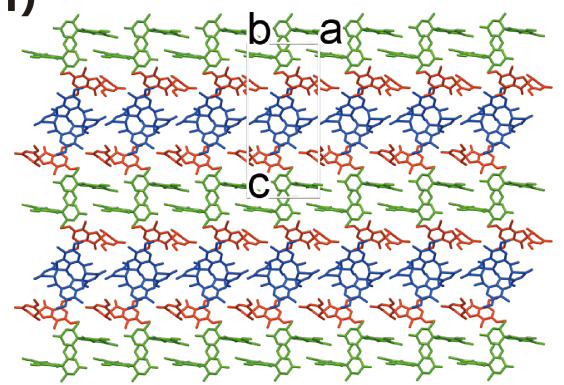

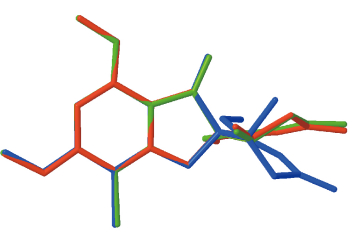

Form V

Figure 5. Single-crystal structures of Forms IV and V. (a-b) POM images of single crystals. (c-d) Unit cells. (e-f) Molecular packing. (g-h) Molecular overlay. Note that c), d) and f) are viewed along the b-axis, while e) is viewed along the a-axis. For each polymorph, molecules 1, 2 and 3 are marked in green, red and blue, respectively. 
Table 1. Crystallographic and thermodynamic parameters of GSF polymorphs.

\begin{tabular}{|c|c|c|c|c|c|c|c|c|}
\hline & Form I & Form II & Form III & Form IV & Form V & GSF-PEG $8000 \mathrm{IC}$ & GSF-PBA IC & GSF-PES IC \\
\hline Yr. discovered, & $1947^{25}$ & $2013^{22}$ & $2013^{22}$ & This work & This work & $2014^{18}$ & This work & This work \\
\hline Method $^{[\mathrm{a}]}[\mathrm{ref}]$ & $\mathrm{SC}$ & $\mathrm{MC}$ & $\mathrm{MC}$ & $\mathrm{MC}$ & $\mathrm{MC}$ & $\mathrm{MC}$ & $\mathrm{MC}$ & $\mathrm{MC}$ \\
\hline Yr. str. Solved, & $1977^{21}$ & $2018^{23}$ & $2020^{24}$ & This work & This work & This work & This work & This work \\
\hline Method $^{[\mathrm{b}]}[\mathrm{ref}]$ & $\mathrm{SCXD}^{21}$ & $\mathrm{SCXD}^{23}$ & $\mathrm{SCXD}^{24}$ & SCXD & SCXD & SCXD & SCXD & SCXD \\
\hline Nucleation in $\mathrm{MC}^{[\mathrm{c}]}$ & $\mathrm{SN}$ & PT & $\mathrm{SN}$ & PT & $\mathrm{SN}$ & $\mathrm{SN}$ & $\mathrm{SN}$ & $\mathrm{SN}$ \\
\hline CCDC number ${ }^{[\mathrm{d}]}$ & 1937668 & 1918292 & 1893059 & 190529 & 190515 & 2121359 & 2121358 & 2121357 \\
\hline$T(\mathrm{~K})$ & 298 & 298 & 298 & 298 & 298 & 100 & 100 & 100 \\
\hline Crystal system & Tetragonal & Orthorhombic & Triclinic & Orthorhombic & Monoclinic & Monoclinic & Monoclinic & Monoclinic \\
\hline Space group & $P 4_{1}(76 \#)$ & $P 2{ }_{1} 2{ }_{1}{ }_{1}(19 \#)$ & P1 (1\#) & $P 2{ }_{1} 2{ }_{1}{ }_{1}(19 \#)$ & $P 2_{1}(1 \#)$ & $I 2(5 \#)$ & $I 2(5 \#)$ & $I 2(5 \#)$ \\
\hline $\mathrm{a}(\AA)$ & $8.97400(10)$ & $11.7669(3)$ & $11.3540(2)$ & $8.47020(10)$ & $11.8711(2)$ & $11.6874(10)$ & $11.74660(10)$ & $11.6870(3)$ \\
\hline $\mathrm{b}(\AA)$ & $8.97400(10)$ & $11.9886(3)$ & $11.9110(2)$ & $11.82950(10)$ & $8.44340(10)$ & $8.6513(7)$ & $8.63920(10)$ & $8.6507(2)$ \\
\hline $\mathrm{c}(\AA)$ & $19.8928(4)$ & $24.3068(6)$ & $12.7608(2)$ & $51.6400(6)$ & $25.7281(3)$ & $20.205(2)$ & $20.5457(2)$ & $20.4998(7)$ \\
\hline$\alpha\left(^{\circ}\right)$ & 90 & 90 & $79.8440(10)$ & 90 & 90 & 90 & 90 & 90 \\
\hline $\mathrm{B}\left({ }^{\circ}\right)$ & 90 & 90 & $89.1950(10)$ & 90 & $90.1840(10)$ & $98.641(9)$ & $98.8120(10)$ & $99.412(3)$ \\
\hline$\gamma\left({ }^{\circ}\right)$ & 90 & 90 & $83.4730(10)$ & 90 & 90 & 90 & 90 & 90 \\
\hline Volume $\left(\AA^{3}\right)$ & 1602.02 & 3428.93 & 1687.66 & 5174.24 & 2578.78 & 2019.90 & 2060.39 & 2044.64 \\
\hline $\mathrm{Z}$ & 4 & 8 & 4 & 12 & 6 & 4 & 4 & 4 \\
\hline$Z^{\prime}$ & 1 & 2 & 4 & 3 & 3 & 1 & 1 & 1 \\
\hline$\rho\left(\mathrm{g} / \mathrm{cm}^{3}\right)$ & 1.463 & 1.367 & 1.388 & 1.358 & 1.363 & 1.160 & 1.137 & 1.146 \\
\hline R-factor & 2.98 & 4.07 & 3.01 & 3.15 & 3.04 & 7.86 & 4.44 & 4.34 \\
\hline$T_{\mathrm{m}}{ }^{[\mathrm{e}]}\left({ }^{\circ} \mathrm{C}\right)$ & 221 & 215 & 205 & 204 & 191 & 153 & 167 & 161 \\
\hline$T_{\mathrm{m}}^{[\mathrm{f}]}\left({ }^{\circ} \mathrm{C}\right)$ & $221( \pm 0.0)$ & $215( \pm 0.25)$ & $207( \pm 0.85)$ & $205( \pm 0.57)$ & 189 & NA & NA & NA \\
\hline$\Delta H_{\mathrm{m}}^{[\mathrm{g}]}(\mathrm{kJ} / \mathrm{mol})$ & $114( \pm 3.73)$ & $86( \pm 2.96)$ & $79( \pm 1.50)$ & $81( \pm 1.82)$ & $76( \pm 1.9)$ & NA & NA & NA \\
\hline$\alpha_{\mathrm{v}}{ }^{[\mathrm{h}]}\left(10^{6} / \mathrm{K}\right)$ & 154 & 149 & 146 & 157 & 132 & NA & NA & NA \\
\hline
\end{tabular}

[a] Methods of polymorph discovery: SC, solution crystallization; MC, melt crystallization.

[b] Methods of structural determination: SCXD, single-crystal X-ray diffraction.

[c] Nucleation mode in melt crystallization: SN, self-nucleation; PT, polymorphic transformation.

[d] The CCDC numbers and the crystallographic parameters of Forms I, II and III presented in Table 1 are cited from our previous work. ${ }^{24}$

[e] $T_{\mathrm{m}}$ was determined using hot-stage microscopy at a heating rate of $50{ }^{\circ} \mathrm{C} / \mathrm{min}$.

[f] $T_{\mathrm{m}}$ was determined using DSC at a heating rate of $10^{\circ} \mathrm{C} / \mathrm{min}$ with $n=3$ for all forms except Form V ( $\left.n=1\right)$ (Figure S3).

[g] $\Delta H_{\mathrm{m}}$ was determined using DSC at a heating rate of $50^{\circ} \mathrm{C} / \mathrm{min}$ to avoid the phase conversion of metastable polymorphs $(n=3)(\mathbf{F i g u r e} 4 \mathbf{c})$.

$[\mathrm{h}] \alpha_{\mathrm{v}}$ refers to the volumetric thermal expansion coefficient. 
Intriguingly, Forms IV and V are quasi-isostructural. Their cell parameters are in close correspondence. Two of the axis lengths are very similar, but a third axis of Form IV has a length two times longer than that of Form V. Both polymorphs have three conformationally dependent molecules (molecules 1,2 and 3, marked in blue, green and yellow, respectively, in Figure 5). The conformation of each molecule in the two polymorphs has nearly the same torsion angles (Table 2). For each polymorph, molecule 1 is very similar to molecule 2 but quite different from molecule 3, especially for torsion angles $\theta 2$ (C7-C4-C5-C14), $\theta 3$ (O2-C3-C4-O3) and $\theta 4$ (C4-C5-C6-C1) (Table $\mathbf{2}$ and Figure $\mathbf{5} \mathbf{g}$-h). The crystal packing arrangements in two polymorphs are also very similar, especially for molecules 2 and 3. Both polymorphs exhibit one-dimensional molecular stacking columns along the $b$ - and $a$-axes, and the columns exhibit an extended layered arrangement along the c-axis. However, they have different melting points, PXRD patterns, Raman spectra, crystal growth rates and crystal habits. Quasi-isostructurality was also found for Forms II and III of GSF (Table 1 and Figure S4). Interestingly, Forms II and IV cannot self-nucleate from neat GSF melts but only transform from their quasi-isostructural counterparts, Forms III and V, respectively. The mechanism of this phenomenon deserves further investigation.

Table 2. Torsional angles of molecules in GSF Forms IV and V.

\begin{tabular}{lllllll}
\hline \multirow{2}{*}{ Torsion angles } & \multicolumn{2}{l}{ Form IV } & \multicolumn{5}{l}{ Form V } \\
\cline { 2 - 7 } & Mol. 1 & Mol. 2 & Mol. 3 & Mol. 1 & Mol. 2 & Mol. 3 \\
\hline 日1(C3-C4-C7-C8) & 116.45 & 113.05 & 119.29 & 115.74 & 115.77 & 121.67 \\
$\theta 2$ (C7-C4-C5-C14) & 45.00 & 43.68 & -54.58 & 45.12 & 41.18 & -54.11 \\
$\theta 3($ O2-C3-C4-O3) & 45.39 & 45.77 & 82.05 & 45.50 & 46.56 & 82.37 \\
$\theta 4($ C4-C5-C6-C1) & -54.42 & -53.24 & 57.21 & -54.31 & -53.79 & 55.58 \\
\hline
\end{tabular}

Cross-nucleation between Forms IV and V. We observed complicated cross-nucleation phenomena between Forms IV and V (Figure S5) and hence measured their crystal growth rates as a function of temperature (shown in Figure 6) to better understand their phase behaviors. Form 
$\mathrm{V}$ is the domain phase below $174{ }^{\circ} \mathrm{C}$. Its growth rate reaches a maximum at $178{ }^{\circ} \mathrm{C}$ (this temperature is defined as $T_{\max }$ here) and then drops rapidly. Interestingly, Form IV has the same $T_{\max }$ as Form V, $178{ }^{\circ} \mathrm{C}$. Above $178{ }^{\circ} \mathrm{C}$, Form IV grows much faster than Form V. Therefore, if we seed Form V above $178{ }^{\circ} \mathrm{C}$, Form IV will cross-nucleate on the surface of the mother phase, while seeding Form IV below $174{ }^{\circ} \mathrm{C}$ results in the cross-nucleation of Form V on Form IV seeds. At $174-178{ }^{\circ} \mathrm{C}$, the two forms will interactively nucleate on each other and grow together with similar growth rates. The nucleation and growth of Forms IV and V provides a good case to demonstrate that cross-nucleation is a kinetically controlled process. ${ }^{26-28}$

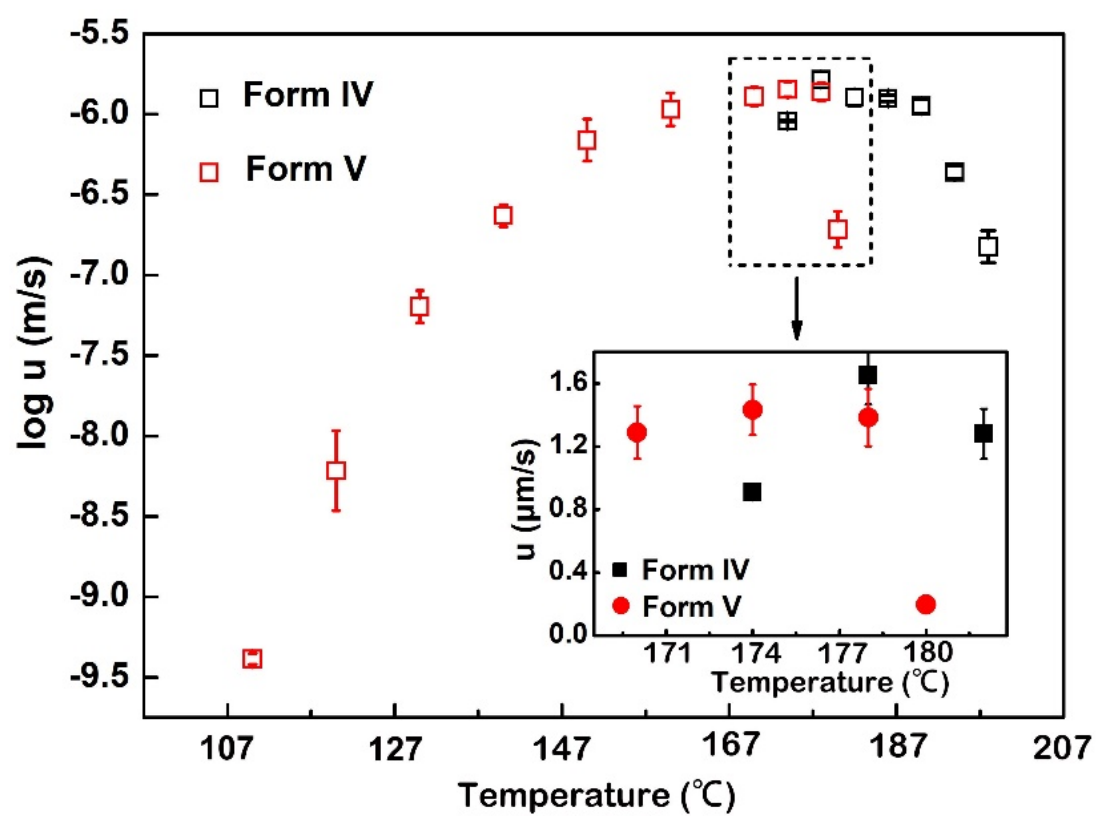

Figure 6. Growth rates of GSF Form IV and Form V in the GSF melt as a function of temperature. Each data point is the mean of at least three separate measurements.

Thermal expansion coefficients (TECs) of GSF polymorphs. We measured the TECs $\left(\alpha_{\mathrm{v}}=\right.$ $\mathrm{d} \ln V / \mathrm{d} T)$ of Forms II-V. The TECs of Forms I and II were also redetermined for comparison. All polymorphs have typical TEC values of organic crystals $\left(100-300 \times 10^{-6} / \mathrm{K}\right): 154 \times 10^{-6} / \mathrm{K}$ for Form I, $149 \pm 7 \times 10^{-6} / \mathrm{K}$ for Form II $(n=3), 146 \times 10^{-6} / \mathrm{K}$ for Form III, $157 \times 10^{-6} / \mathrm{K}$ for Form IV 
and $132 \times 10^{-6} / \mathrm{K}$ for Form V (Figure 7 and Tables S1-7 ). The TECs of Forms I and II were lower than the reported values. ${ }^{23}$

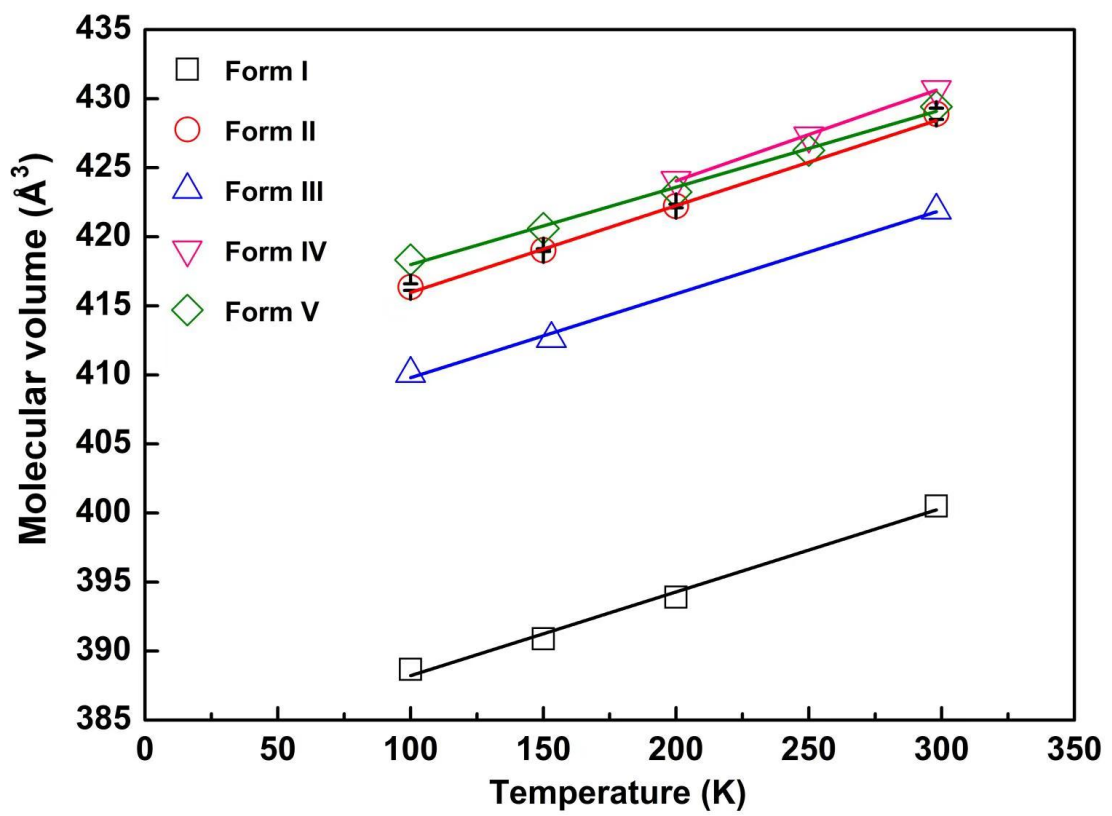

Figure 7. Molecular volumes of the GSF polymorphs at 100, 150, 200, 250 and $298 \mathrm{~K}$.

Single-crystal structure of the GSF-PEG IC. GSF-PEG IC was disclosed in $2014 ;{ }^{18}$ however, its single-crystal structure has not been elucidated thus far. We tried to grow single crystals by partially melting polycrystalline spherulites to yield a single-crystal nucleus but failed because Form $\mathrm{V}$ always grows from where the IC originally existed near its $T_{\mathrm{m}}$. Fortunately, as the content of PEG is increased to $60 \%$, GSF-PEG 8000 IC spontaneously nucleates and grows as single crystals at $120^{\circ} \mathrm{C}$ (shown in Figure 8a) with sufficient size and quality. We collected the SCXRD data at $100 \mathrm{~K}$ and successfully solved its single-crystal structure (shown in Table 1). The GSFPEG IC crystallizes in a monoclinic space group (space group I2), with $a=11.687 \AA, b=8.651$ $\AA, c=20.205 \AA, \beta=98.642^{\circ}, Z=4$, and $Z^{\prime}=1$, which are close to the previously reported data indexed from PXRD data by Huang's group. ${ }^{18}$ However, the PEG chains included in IC channels are disordered (shown in Figure S6). Huang's group also reported the disordered conformation of 
PEG oligomers included in diflunisal channels and attributed it to the lack of intermolecular interactions between guest PEG and host diflunisal. ${ }^{29}$ We removed the disordered PEG 8000 molecules by the Use Solvent Mask function of Olex 2 software and show the crystal structure in Figure 8d. The GSF-PEG IC is isostructural with respect to previously reported GSF channel-type solvates, ${ }^{30}$ which will be discussed in the Discussion Section.
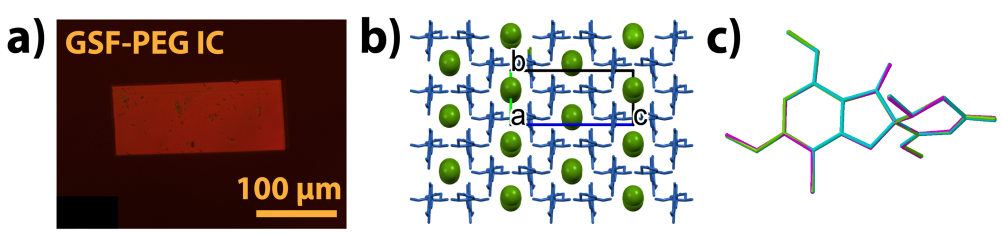

d) GSF-PEG IC
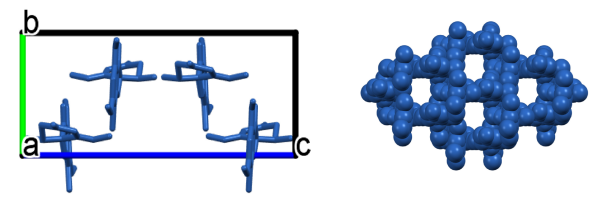

e) GSF-PBA IC
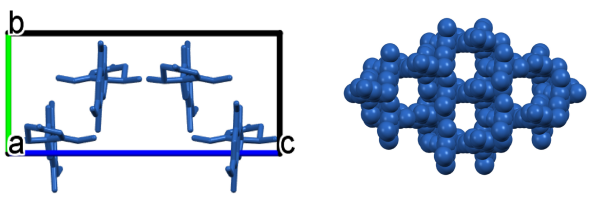

f) GSF-PES IC
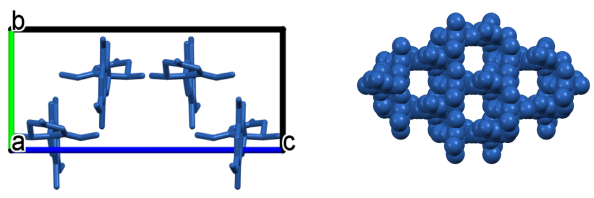

Figure 8. Crystal structures of GSF-polymer ICs. (a) POM image of GSF-PEG 8000 IC single crystal grown from a melt. (b) Crystal packing of the GSF-PEG 8000 IC with the disordered PEG 8000 occupying the cavities as shown in green. (c) Overlay of GSF molecules in GSF-PEG (green), GSF-PBA (blue) and GSF-PES (purple) ICs. (d) Crystal structure of the GSF-PEG IC. (e) Crystal structure of the GSF-PBA IC. (f) Crystal structure of the GSF-PES IC. Guest polymers are not shown in (d-f).

Influence of $M_{\mathrm{w}}$ and PEG content on the polymorphic behavior of GSF. We further investigated the dependence of the polymorphic behavior of the GSF dispersion with PEG/PEO on the $M_{\mathrm{w}}$ and content of PEG/PEO. GSF-PEG/PEO physical mixtures were melted at $230{ }^{\circ} \mathrm{C}$, quenched at room temperature, and then aged at various temperatures from $50{ }^{\circ} \mathrm{C}$ to $140{ }^{\circ} \mathrm{C}$. The 
crystallization process and the resultant crystals were investigated with hot-stage microscopy by $T_{\mathrm{m}}$ detection. The results are depicted in Figure 9 in the form of two histograms.

As shown in Figure 9a, Form I, the most stable polymorph, can nucleate randomly at all temperatures studied for all systems; thus, we will not discuss this polymorph below. Neat GSF randomly nucleates as Forms III and I above $80^{\circ} \mathrm{C}$, and only Form I crystallizes below $80{ }^{\circ} \mathrm{C}$. The addition of 10\% PEG 200 facilitates the formation of Form $\mathrm{V}$ at all temperatures investigated and Form III above $90{ }^{\circ} \mathrm{C}$. As the $M_{\mathrm{w}}$ of PEG is increased to more than $1000, \mathrm{PEG} / \mathrm{PEO}$ with various $M_{\mathrm{w}}$ values exhibits different effects on GSF polymorphism. At low temperature, the GSF-PEG IC replaces GSF Form V as the domain phase. At high temperature, Forms III and V regain the chance of nucleation. This boundary temperature increases with increasing $M_{\mathrm{w}}$ of PEG/PEO $\left(100{ }^{\circ} \mathrm{C}\right.$ for PEG 1000 and $8000,110^{\circ} \mathrm{C}$ for PEG $10 \mathrm{k}$ and $100 \mathrm{k}$, and $120^{\circ} \mathrm{C}$ for PEG $1000 \mathrm{k}$ ). This indicates that PEG/PEO with various $M_{\mathrm{w}}$ values facilitates the nucleation of Form V and ICs, and high $M_{\mathrm{w}}$ favors the formation of the GSF-PEG/PEO IC.

As shown in Figure 9b, for neat GSF, only two polymorphs (Forms I and III) spontaneously nucleated. Considering that Form III has the opportunity to transform to Form II, a total of three polymorphs might be observed in neat GSF.

By adding 10-50\% PEG 8000, three true polymorphs of GSF (Forms I, III and V) and the GSFPEG IC can spontaneously nucleate from the co-melt. Because Forms II and IV yield by phase transformation and/or cross nucleation, a total of six solid forms can be obtained from GSF dispersions with PEG. When the PEG 8000 content increases to $60 \%$, only Form I and the GSFPEG IC crystallize. When the PEG 8000 content is higher than $70 \%$, Form I is the only solid phase at all temperatures. In the commercial formulation, the weight ratio of drug to PEG is $1: 9$. At this 
ratio, GSF crystallizes as Form I. This may be one of the reasons why Forms IV and V were not discovered for almost half a century after the GSF-PEG formulation was marketed.
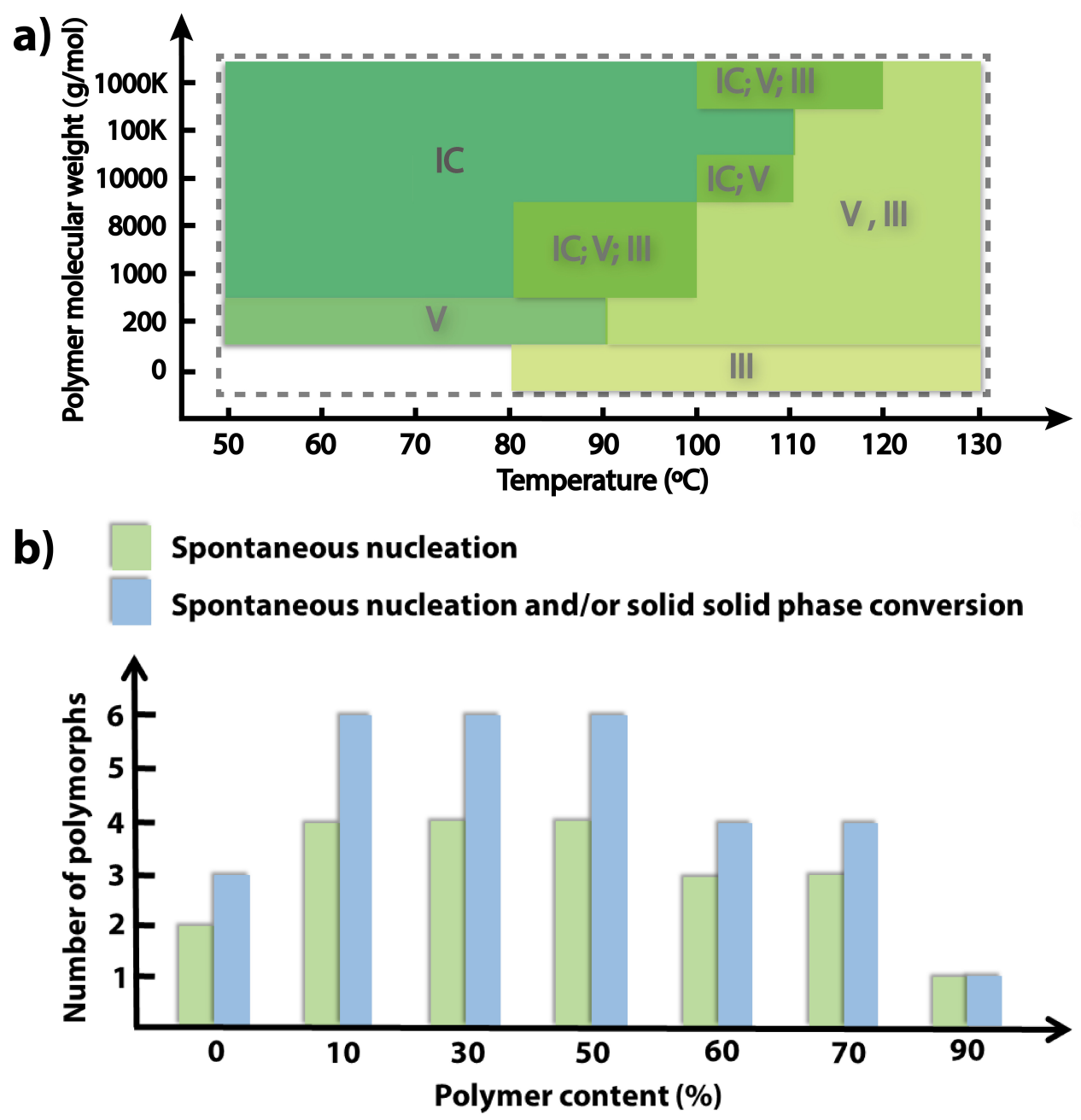

Figure 9. Polymorphism of GSF in the presence of PEG/PEO. (a) Influence of the $M_{\mathrm{w}}$ of PEG/PEO on GSF polymorphism at various temperatures. The polymer content is $10 \%$, and the gray dotted frame indicates that Form I can nucleate randomly in this region. (b) Influence of the PEG 8000 content on the phase number of GSF.

Thermodynamic stability and solid form landscape of GSF polymorphs. We employed DSC and hot-stage microscopy to evaluate the thermodynamic stability of GSF polymorphs and establish the solid form landscape of GSF. Moderate heating at $10^{\circ} \mathrm{C} / \mathrm{min}$ was employed for $T_{\mathrm{m}}$ determination, while fast heating at $50^{\circ} \mathrm{C} / \mathrm{min}$ was used to measure the melting enthalpy $\left(\Delta H_{\mathrm{m}}\right)$ to 
minimize the phase conversion of Form $V$ to more stable polymorphs (Table 1, Figures 3c and S2). All thermodynamic parameters of GSF polymorphs are listed in Table 1. The $T_{\mathrm{m}} \mathrm{s}$ of Forms I, II, and III and the melting enthalpies of Forms I and II are consistent with previously reported data. ${ }^{23}$ The $\Delta H_{\mathrm{m}}$ of Form III was accurately measured for the first time in this work, which benefits from the successful preparation of crystallographically pure samples. The Gibbs energy differences between each polymorph and liquid $\left(\Delta G_{\mathrm{v}}\right)$ were calculated according to the Hoffman equation shown in Equation (1), which presents the thermodynamic driving force for crystallization.

$$
\Delta G_{\mathrm{v}}=\frac{\Delta H_{\mathrm{m}}\left(T-T_{\mathrm{m}}\right) T}{T_{\mathrm{m}}^{2}}
$$

$\Delta G_{\mathrm{v}}$ versus temperature is plotted in Figure $\mathbf{1 0}$ for each GSF polymorph. According to the thermodynamic parameters measured by DSC and phase conversions based on experimental observations, a solid form landscape of GSF was established and is shown in Figure 11.

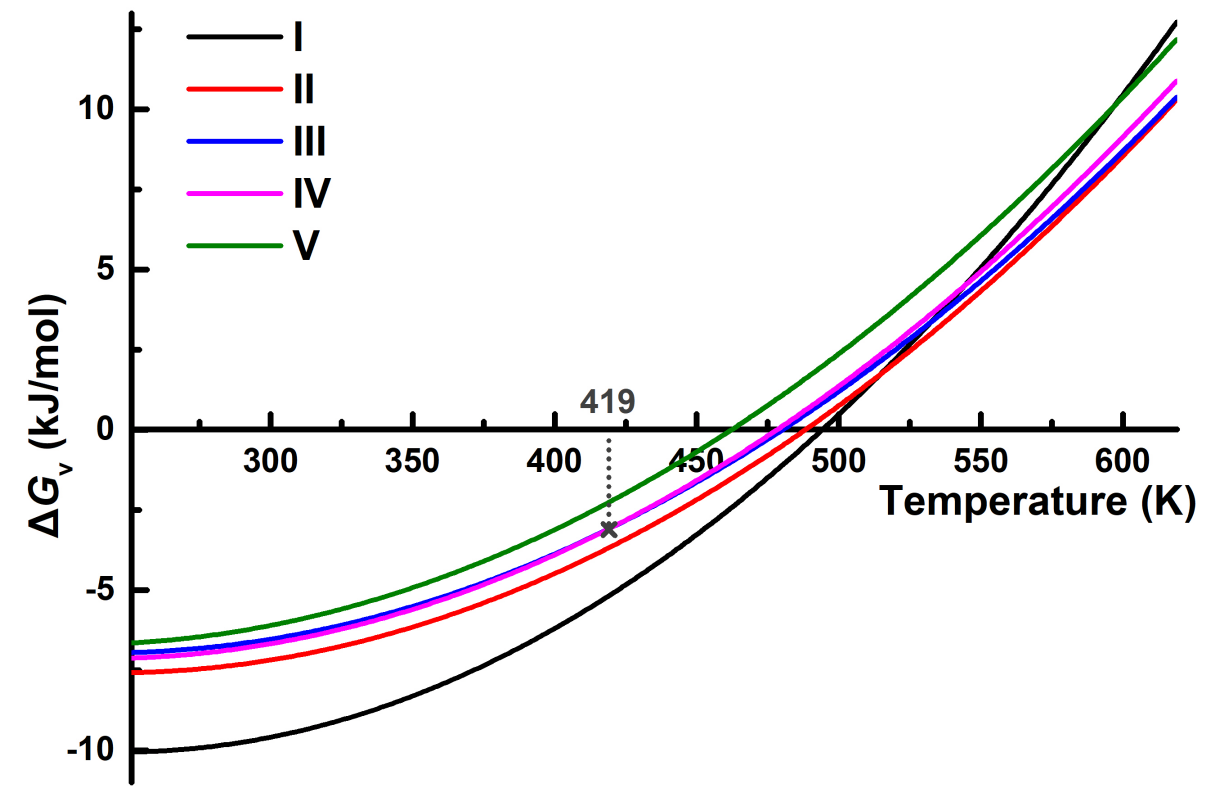

Figure 10. Plots of $\Delta G_{\mathrm{v}}$-temperature for GSF polymorphs based on the predictions of the Hoffman equation. 


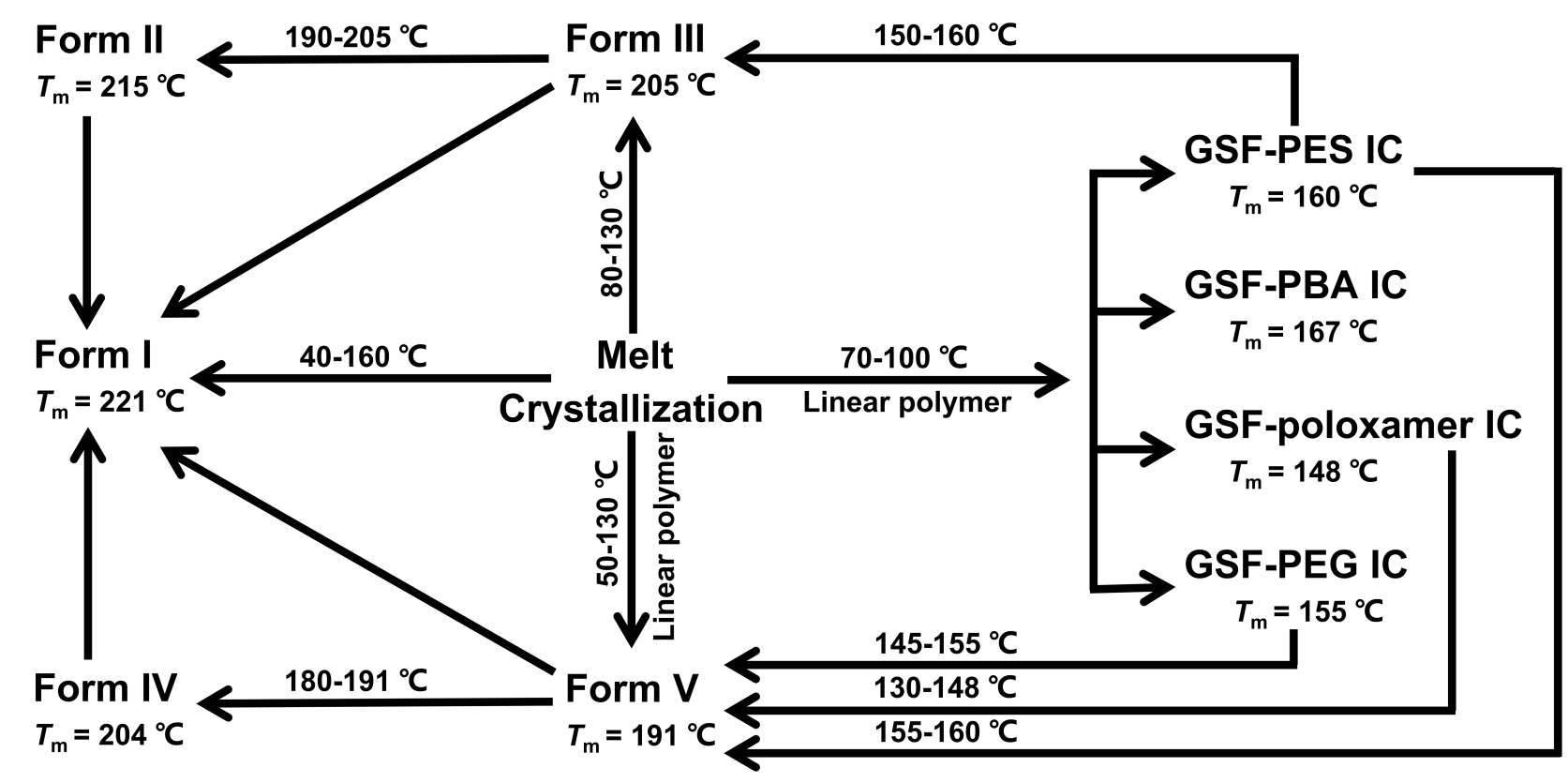

Figure 11. Solid form landscape of GSF, including true polymorphs and GSF-polymer ICs.

Form I is the most stable polymorph with the highest $T_{\mathrm{m}}$ and the largest $\Delta H_{\mathrm{m}}$ and thus is monotropically related to the other four polymorphs according to the heat-of-fusion rule ${ }^{31}$. Phase transformation from all metastable polymorphs to Form I was observed in DSC curves and under a hot-stage microscope (data not shown). Form II is the second most stable polymorph (with the second highest $T_{\mathrm{m}}$ and $\Delta H_{\mathrm{m}}$ ) and is therefore monotropically related to the other four polymorphs. Phase conversion from Forms III and IV to Form II was observed using a hot-stage microscope (Figure 3). We never observed Form II self-nucleation from neat GSF, but once observed, it spontaneously nucleated from a GSF-PEG 10k (9:1) dispersion (Figure S7). Usually, Form II solid-solid transforms from Form III (Figure S8). Similar to Form II, Form IV never nucleates and usually solid-solid converts from Form V or nucleates from the place where Form V is melting. Form III exhibited a slightly higher $T_{\mathrm{m}}$ but a smaller $\Delta H_{\mathrm{m}}$ than Form IV. According to the heat-offusion rule ${ }^{31}$, Forms III and IV are enantiotropically related, and the intersection temperature is $146^{\circ} \mathrm{C}$, as shown in Figure 11. However, we did not observe solid-solid phase conversion between 
Forms III and IV thus far, which might be attributed to their similar Gibbs free energies and, hence, the small thermodynamic driving force for phase conversion. Form $\mathrm{V}$ is the least stable polymorph, with the lowest $T_{\mathrm{m}}$ and the smallest $\Delta H_{\mathrm{m}}$. V-to-IV phase conversions were observed using both DSC (Figure S3) and hot-stage microscopy (Figure 3). When heated at $10{ }^{\circ} \mathrm{C} / \mathrm{min}$, Form V exhibits an endothermic peak at $189^{\circ} \mathrm{C}$ followed by an exothermic peak and then two endothermic peaks at approximately $204{ }^{\circ} \mathrm{C}$ and $215{ }^{\circ} \mathrm{C}$. Based on the phase conversions in Figure 3, these thermal events were attributed to the melting of Form V, the recrystallization and melting of Form IV, and the melting of Form II transformed from Form IV. In summary, the stability ranking of the five GSF true polymorphs was suggested as follows: Form I $>$ Form II $>$ Form III $\approx$ Form IV $>$ Form V. The GSF-PEG IC has a $T_{\mathrm{m}}$ of $153{ }^{\circ} \mathrm{C}$, lower than that of the least stable true polymorph, Form V. It usually converts to Form V upon melting. The polymorphic landscape shown in Figure 11 describes the rich polymorphism of GSF dispersions with PEG and the complicated phase conversions between GSF solid forms. PEG is the key factor that triggers the formation of such abundant polymorphisms of GSF. This emphasizes the importance of solid form research for PEGbased dispersions.

\section{Discussions}

Why does PEG facilitate the nucleation of GSF Form V and the GSF-PEG IC? To explore the reason why PEG can nucleate GSF Form V and the GSF-PEG IC, we further investigated the influence of polymer structure on the melt crystallization of GSF. Two groups of polymers were selected (chemical structures shown in Figure S9). Group I contains four flexible linear polymers with extremely low glass transition temperatures $\left(T_{\mathrm{g}}\right)$ (below $0{ }^{\circ} \mathrm{C}$ ), including PEG/PEO, PBA, PES and poloxamer. Group II includes one triblock copolymer with large side groups (Soluplus) and three linear polymers with large side groups or stiff main chains (PVP K30, PVP VA64 and 
HPMCAS HF). We fixed the polymer content at $10 \%$ and investigated the influence of the polymer structure on the polymorphic behavior of GSF in dispersions. The results indicate that all polymers in group I can nucleate both Form V and IC, and inversely, polymers in group II cannot (data not shown). The main difference between the two groups of polymers is the geometric radius of the polymer chain, $T_{\mathrm{g}}$ and melt viscosity. We speculate that the first is related to the formation of the IC and that the last two determine the nucleation of Form V.

To elucidate the relationship between the geometric radius of the polymer chain and IC formation, we solved the structures of GSF-PBA and GSF-PES ICs by X-ray crystallography (shown in Table 1, Figure 8 and Figure S10) but failed to determine the structure of the GSFpoloxamer IC due to the difficulty of single-crystal cultivation. Interestingly, both GSF-PBA and GSF-PES ICs have similar unit cell dimensions (Table 1), packing modes (Figure 8e-f) and configurations (Figure 8c) as the GSF-PEG IC. In GSF-PBA and GSF-PES ICs, the linear polymer maintains disorder in the channels of ICs. Three GSF-polymer ICs are isostructural not only with respect to each other but also with respect to GSF solvates with acetonitrile, nitromethane and nitroethane (1:1) (Table S8).$^{30}$ This phenomenon is very similar to that in diflunisal systems, ${ }^{29}$ where the diflunisal-polytetrohydrofuran IC is isostructural with respect to diflunisal solvates with chloroform, hexane and water. In the structure of GSF ICs and solvates, GSF molecules pile up to form tunnels, and solvent molecules and polymers can penetrate these tunnels to form a beaded structure. It is reasonable to speculate that a long chain facilitates the formation of this beaded structure. This can explain why PEG 200 failed to form an IC structure and why higher- $M_{\mathrm{w}}$ PEG/PEO is more likely to nucleate GSF-PEG ICs (Figure 9a). For polymers in group II, the geometric radius might be too large to pass through the tunnels, thus failing to construct IC structures. Therefore, we suggested that the tunnel-type GSF host structure can be stabilized only 
in the presence of guest molecules that can penetrate the tunnels, and hence, the geometric radius of the polymer is a key factor in the formation of GSF-polymer ICs.

The second most significant difference between the two groups of polymers is their $T_{\mathrm{g}}$ values (70 - $11{ }^{\circ} \mathrm{C}$ for group I and $70 \sim 149{ }^{\circ} \mathrm{C}$ for group II). We tested the $T_{\mathrm{g}}$ of neat GSF and GSF dispersions with polymers at $90 \%$ drug loading. The $T_{\mathrm{g}}$ values of polymers were cited from the previous work of other groups. All data are listed in Table 3. All dispersions have a single $T_{\mathrm{g}}$, indicating good miscibility between GSF and all polymers at $90 \%$ drug loading. Neat GSF shows a $T_{\mathrm{g}}$ of $88 \pm 3.4^{\circ} \mathrm{C}$, close to the reported data ${ }^{32}$. GSF dispersions with low- $T_{\mathrm{g}}$ polymers except for the GSF-PEG 1000k dispersion have $T_{\mathrm{g}} \mathrm{s}$ lower than $60^{\circ} \mathrm{C}$, while the $T_{\mathrm{g}} \mathrm{s}$ of dispersions related to high- $T_{\mathrm{g}}$ polymers are close to the $T_{\mathrm{g}}$ of neat GSF. For the GSF-PEO 1000k dispersion at $90 \%$ drug loading, an endothermic peak appears at approximately $50-60{ }^{\circ} \mathrm{C}$ (Figure S11), which might be related to the melting of crystalline PEG and reflects that PEG and GSF are phase-separated in the dispersion. This might be the reason why the GSF-PEG dispersion exhibits a high $T_{\mathrm{g}}$ of 87.1 $\pm 1.2{ }^{\circ} \mathrm{C}$, close to that of neat GSF. We also noticed that there was a significant difference between the changes in heat capacities at $T_{\mathrm{g}}\left(\Delta C_{\mathrm{p}}\right)$ of the dispersions with polymers in the two groups. Dispersions related to polymers in group I exhibit smaller $\Delta C_{\mathrm{p}}$ values $\left(<0.33 \mathrm{~J} \cdot \mathrm{g}^{-1} \cdot \mathrm{K}^{-1}\right)$ than those related to group II polymers $\left(>0.46 \mathrm{~J} \cdot \mathrm{g}^{-1} \cdot \mathrm{K}^{-1}\right)$. 
Table 3. $T_{\mathrm{g}}$ and $\Delta C_{\mathrm{p}}$ of polymers and $90 \%$ GSF-polymer $(n=3)$

\begin{tabular}{lllllccc}
\hline & & \multicolumn{2}{c}{$\Delta C_{\mathrm{g}}\left({ }^{\circ} \mathrm{C} \cdot \mathrm{g}^{-1} \cdot \mathrm{K}^{-1}\right)$} & \multicolumn{2}{c}{ Nucleation } \\
\cline { 3 - 7 } & & Polymer & $\begin{array}{l}90 \% \mathrm{GSF} \\
\text {-polymer }\end{array}$ & $\begin{array}{l}90 \% \mathrm{GSF} \\
\text {-polymer }\end{array}$ & \multicolumn{2}{c}{ Form V } & IC \\
\hline Group I & PBA & $-60^{33}$ & $61.0 \pm 2.0$ & $0.315 \pm 0.052$ & $\sqrt{ }$ & $\sqrt{ }$ \\
& PES & $-11^{34}$ & $69.5 \pm 1.7$ & $0.320 \pm 0.049$ & $\sqrt{ }$ & $\sqrt{ }$ \\
& Poloxamer & $-60^{35}$ & $58.6 \pm 3.0$ & $0.276 \pm 0.074$ & $\sqrt{ }$ & $\sqrt{ }$ \\
& PEG 200 & $-70^{36}$ & $35.5 \pm 2.2$ & $0.272 \pm 0.049$ & $\sqrt{ }$ & $\sqrt{ }$ \\
& PEG 1000 & $-61^{37}$ & $54.0 \pm 1.8$ & $0.260 \pm 0.085$ & $\sqrt{ }$ & $\sqrt{ }$ \\
& PEG 8000 & $-20^{36}$ & $59.3 \pm 1.2$ & $0.267 \pm 0.110$ & $\sqrt{ }$ & $\sqrt{ }$ \\
& PEG 10k & $-20^{38}$ & $58.5 \pm 3.8$ & $0.266 \pm 0.024$ & $\sqrt{ }$ & $\sqrt{ }$ \\
& PEG 100k & $-47^{36}$ & $63.9 \pm 1.8$ & $0.223 \pm 0.015$ & $\sqrt{ }$ & $\sqrt{ }$ \\
& PEG 1000k & $-53^{38}$ & $87.1 \pm 1.2$ & $0.280 \pm 0.049$ & $\sqrt{ }$ & $\sqrt{ }$ \\
Group II & PVP K30 & $149^{39}$ & $89.8 \pm 1.0$ & $0.461 \pm 0.007$ & $\times$ & $\times$ \\
& PVP VA64 & $101^{39}$ & $86.4 \pm 1.8$ & $0.522 \pm 0.074$ & $\times$ & $\times$ \\
& Soluplus & $70^{39}$ & $83.3 \pm 0.5$ & $0.471 \pm 0.040$ & $\times$ & $\times$ \\
& HPMC AS & $121^{40}$ & $85.6 \pm 2.7$ & $0.489 \pm 0.039$ & $\times$ & $\times$ \\
\hline
\end{tabular}

${ }^{*} T_{\mathrm{g}}$ and $\Delta C_{\mathrm{p}}$ of GSF were determined to be $88 \pm 3.4{ }^{\circ} \mathrm{C}$ and $0.379 \pm 0.015 \mathrm{~J} \cdot \mathrm{g}^{-1} \cdot \mathrm{K}^{-1}$, respectively, in this work.

${ }^{+} \Delta C_{\mathrm{p}}$ is defined as the difference between the heat capacities of supercooled liquid and glass.

The third most significant difference between polymers in the two groups is melt viscosity. Polymers in group $\mathrm{I}^{39,41-42}$ have much lower melt viscosity than polymers in group II. ${ }^{39,43-44}$ Therefore, it is reasonable to speculate that GSF dispersions related to polymers in group I have lower melt viscosities than those related to polymers in group II. At the same temperature, low $T_{\mathrm{g}}$ and viscosity result in high molecular mobility ${ }^{45}$. Hence, GSF in dispersions with low- $T_{\mathrm{g}}$ polymers has higher molecular mobility than dispersions related to high- $T_{\mathrm{g}}$ polymers. Cai's group also proved that the addition of PEG enhances the molecular mobility of amorphous GSF. ${ }^{20}$ For these reasons, we suggested that molecular mobility might be one of the key factors promoting the nucleation of Form V.

Nucleation is the key step for crystallization. According to classical nucleation theory, ${ }^{46}$ the activation energy of nucleation $\left(\Delta G_{\mathrm{v}}\right)$ can be determined by both the surface energy at the crystalamorphous interface $(\sigma)$ and the Gibbs free energy difference between the amorphous and crystal phases $\left(\Delta G_{\mathrm{v}}\right)$, as shown in Equation (2). 


$$
\Delta G^{*}=\frac{16 \pi \sigma^{3}}{3 \Delta G_{\mathrm{v}}^{2}}
$$

The $\Delta G_{\mathrm{v}}$ values of GSF polymorphs at various temperatures are shown in Figure 10. Form V, the least stable polymorph, had the lowest $\Delta G_{\mathrm{v}}$, while Form I, the most stable polymorph, had the highest $\Delta G_{\mathrm{v}}$. This is consistent with the well-known rule where the stable polymorph always has the lowest Gibbs free energy. Because the least stable polymorph has the highest state of disorder, Form $\mathrm{V}$ is predicted to have a lower $\sigma$ than the other more stable polymorphs. Therefore, $\sigma$ is a favorable factor and $\Delta G_{\mathrm{v}}$ is an unfavorable factor for the nucleation of Form $\mathrm{V}$.

According to the hypothetical interplay between $\sigma$ and $\Delta G_{\mathrm{v}}$ as a function of molecular mobility suggested by Van den Mooter's group, ${ }^{4}$ as the molecular mobility of the drug is high enough, the $\sigma$ term is much more pronounced than the $\Delta G_{\mathrm{v}}$ term; thus, metastable polymorphs are kinetically preferred. In contrast, if the mobility of drug molecules is relatively low, $\sigma$ is less significant than $\Delta G_{\mathrm{v}}$, and therefore, the nucleation barrier will be lower for more stable forms. Our observation of GSF polymorphism supports this hypothesis that the addition of polymers in group I (low $T_{\mathrm{g}}$ and melt viscosity) increases the molecular mobility of amorphous $\mathrm{GSF}^{20}$ and thus facilitates the nucleation of the least stable form, Form $\mathrm{V}$, while the introduction of polymer in group II (high $T_{\mathrm{g}}$ and melt viscosity) depresses the molecular mobility of GSF and inhibits the nucleation of Form $\mathrm{V}$. The addition of a miscible polymer will decrease the crystal-liquid surface energy and depress the Gibbs free energy of amorphous GSF and, thus, $\Delta G_{\mathrm{v}}$. Therefore, further experiments are needed to further clarify the mechanism by which polymers in group I can trigger the nucleation of Form V, which is beyond the scope of this work. Considering that different polymorphs might exhibit different solubilities, dissolution behaviors and bioavailabilities, the polymorphic behavior of PEG-based dispersions must be given full attention. 
High-Z' structure in GSF polymorphs. GSF has five polymorphs, among which $80 \%$ polymorphs (Forms II-V) are accessible only from melts and have high-Z' structures. The high frequency of high-Z' structures may be related to the melt crystallization and the chirality of GSF molecules ${ }^{47}$. Solid-solid phase transformation can be observed from a high-Z' phase (Form III with $Z^{\prime}=4$, Form IV with Z'=3) to a phase with a lower Z' (Form II with Z'=2, Form I with Z'=1). As mentioned above, Forms II and IV cannot self-nucleate and are only converted from Forms III and V, respectively. For III-to-II phase conversion, the molecular packing arrangements in Forms III and II are very similar; therefore, only slight conformation adjustment (low interconversion barrier) is needed for phase conversion to obtain the benefit of reducing the Gibbs energy. A similar situation occurs in IV-to-V phase conversion, in which Forms IV and V have similar molecular packing arrangements and the same Z' value of three. Nangia's group reported their survey on high-Z' structures in 2006 and showed that the incidence of Z'>1 structures is higher for both melt and sublimation crystallization than solution growth, and this preference is dramatic for $Z^{\prime} \geq 3$ structures. ${ }^{48}$ In our previous work, nicotinamide grows a $Z^{\prime}=1$ stable polymorph from solution and another $Z^{\prime}=4$ metastable polymorph by solution growth in the presence of isoxyl but yields three $Z^{\prime}=2$, one $Z^{\prime}=4$ and one $Z^{\prime}=20$ structures by melt crystallization. ${ }^{49}$ In this work, GSF gives one $Z^{\prime}=2$, two $Z^{\prime}=3$ and one $Z^{\prime}=4$ structures by melt crystallization and only one $Z^{\prime}=1$ stable structure by solution crystallization. The high occurrence of high-Z' structures makes GSF a suitable compound for high-Z' research and for testing the capability of the theoretical model for crystal structure prediction, because prediction of a possible high-Z' structure is still a great challenge for current polymorph generation algorithms. ${ }^{50}$ 


\section{Conclusion}

We reported the rich polymorphism and complicated phase behaviors of GSF in PEG-based dispersions. In total, five true polymorphs and one IC crystallize from dispersions, among which two new polymorphs (Forms IV and V) were discovered in this work. The single-crystal structure of the GSF-PEG IC was successfully solved for the first time. Although several new polymorphs of drugs have been discovered by crystallization from a polymer matrix, such as indomethacin Form $\tau$ in $\mathrm{PEG},{ }^{4}$ olanzapine Form IV in PVP,${ }^{51}$ topiramate Form II in PEG,${ }^{6}$ and islatravir Form V from EVA or PCL during hot melt extrusion, ${ }^{52}$ to the best of our knowledge, GSF is the first clinical drug that displays such rich polymorphism (six solid forms) in dispersions. This further convince scientists in polymorphism research that polymer addition is an alternative strategy to discover new polymorphs, which cannot be neglected in polymorphism screening.

The possible mechanism of the rich polymorphism of GSF in PEG-based dispersions was suggested to be the enhancement in molecular mobility (lower $T_{\mathrm{g}}$ and viscosity) for the formation of two new polymorphs and the size effect for IC formation because small flexible linear polymers (PEG/PEO, poloxamer, PBA and PES) facilitate the nucleation of two new phases and ICs, while large polymers or polymers with rigid chains (PVPK30, PVPVA64, Soluplus and HPMCAS) cannot. Considering that different polymorphs might exhibit different solubilities, dissolution behaviors and bioavailabilities, our discovery will inspire the pharmaceutical industry and shows that polymorphism control of drug in semi-crystalline PEG dispersions should be given full attention to achieve reproducible and consistent pharmaceutical performance. The story of GSF and PEG continues on its own. 


\section{ASSOCIATED CONTENT}

Supporting Information of this article is available free of charge on the ACS Publications website, including a PDF document named "Supplementary Data 1" and a ZIP document of the relevant 29 CIF files titled "Supplementary Data 2". This PDF document contains various characterization of GSF polymorphs and GSF-polymer ICs, including POM images, PXRD patterns, DSC curves, single-crystal structures, chemical structures of materials used in this work and cystallographic parameters of GSF true polymorphs, ICs and solvates. These CIF data can be obtained free of charge from The Cambridge Crystallographic Data Centre via www.ccdc.cam.ac.uk/data_request/cif.

\section{AUTHOR INFORMATION}

\section{Corresponding Author}

*Ming Lu - School of Pharmaceutical, Sun Yat-sen University, Guangzhou, China;

ORCID: 0000-0002-2622-1528;

E-mail: luming3@mail.sysu.edu.cn

\section{Authors}

Xiao Ou - School of Pharmaceutical Sciences, Sun Yat-sen University, Guangzhou, China;

ORCID: 0000-0002-3385-9781;

Shuting Li - School of Pharmaceutical Sciences, Sun Yat-sen University, Guangzhou, China;

Yunyun Chen - School of Pharmaceutical Sciences, Sun Yat-sen University, Guangzhou, China;

Haowei Rong - School of Pharmaceutical Sciences, Sun Yat-sen University, Guangzhou, China; 
Ao Li - School of Pharmaceutical Sciences, Sun Yat-sen University, Guangzhou, China.

\section{Author Contributions}

The manuscript was written with contributions of all authors. All authors have given approval to the final version of the manuscript. $\$$ These authors contributed equally.

\section{Notes}

The authors declare no competing financial interest.

\section{ACKNOWLEDGMENT}

We thank Professor Ting Cai (China Pharmaceutical University) for his valuable discussion. This work was financially supported by the Guangdong Basic and Applied Basic Research Foundation (No. 2020A1515010782) and the Guangzhou Basic and Applied Basic Research Foundation (No. 202102080327).

\section{REFERENCES}

1. Zhang, J.; Shi, Q.; Guo, M.; Liu, Z.; Cai, T. Melt crystallization of indomethacin polymorphs in the presence of poly(ethylene oxide): selective enrichment of the polymer at the crystal-liquid interface. Mol. Pharmaceutics 2020, 17, 2064-2071.

2. Sanabria Ortiz, K.; Hernández Espinell, J. R.; Ortiz Torres, D.; López-Mejías, V.; Stelzer, T. Polymorphism in solid dispersions. Cryst. Growth Des. 2020, 20, 713-722.

3. Hernández Espinell, J. R.; López-Mejías, V.; Stelzer, T. Revealing polymorphic phase transformations in polymer-based hot melt extrusion processes. Cryst. Growth Des. 2018, 18, 1995-2002. 
4. Van Duong, T.; Lü deker, D.; Van Bockstal, P.-J.; De Beer, T.; Van Humbeeck, J.; Van den Mooter, G. Polymorphism of indomethacin in semicrystalline dispersions: formation, transformation, and segregation. Mol. Pharmaceutics 2018, 15, 1037-1051.

5. Shi, Q.; Zhang, J.; Zhang, C.; Jiang, J.; Tao, J.; Zhou, D.; Cai, T. Selective acceleration of crystal growth of indomethacin polymorphs by low-concentration poly (ethylene oxide). Mol. Pharmaceutics 2017, 14, 4694-4704.

6. Yam, N.; Li, X.; Jasti, B. R. Interactions of topiramate with polyethylene glycol 8000 in solid state with formation of new polymorph. Int. J. Pharm. 2011, 411, 86-91.

7. Docoslis, A.; Huszarik, K. L.; Papageorgiou, G. Z.; Bikiaris, D.; Stergiou, A.; Georgarakis, E. Characterization of the distribution, polymorphism, and stability of nimodipine in its solid dispersions in polyethylene glycol by micro-Raman spectroscopy and powder X-ray diffraction. AAPS. J. 2007, 9, E361-E370.

8. Naima, Z.; Siro, T.; Juan-Manuel, G.-D.; Chantal, C.; René, C.; Jerome, D. Interactions between carbamazepine and polyethylene glycol (PEG) 6000: characterisations of the physical, solid dispersed and eutectic mixtures. Eur. J. Pharm. Sci. 2001, 12, 395-404.

9. Martínez-Ohárriz, M. C.; Martín, C.; Goñi, M. M.; Rodríguez-Espinosa, C.; Tros-Ilarduya, M. C.; Zornoza, A. Influence of polyethylene glycol 4000 on the polymorphic forms of diflunisal. Eur. J. Pharm. Sci. 1999, 8, 127-132.

10. Lacoulonche, F.; Chauvet, A.; Masse, J.; Egea, M.; Garcia, M. An investigation of FB interactions with poly (ethylene glycol) 6000, poly (ethylene glycol) 4000, and poly-ecaprolactone by thermoanalytical and spectroscopic methods and modeling. J. Pharm. Sci. 1998, $87,543-551$. 
11. Oxford, A. E.; Raistrick, H.; Simonart, P. Studies in the biochemistry of micro-organisms: griseofulvin, $\mathrm{C}_{17} \mathrm{H}_{17} \mathrm{O}_{6} \mathrm{Cl}$, a metabolic product of penicillium griseo-fulvum dierckx. Biochem. J. 1939, 33, 240-248.

12. Brian, P. W. Studies on the biological activity of griseofulvin. Ann. Bot. 1949, 13, 59-77.

13. Drugs@fda: Fda-approved drugs. https://www.accessdata.fda.gov/scripts/cder/daf/index.cf$\mathrm{m}$ ?event $=$ overview.process $\& A p p 1 \mathrm{No}=050051($ accessed 2021-02-21).

14. Atkinson, R. M.; Bedford, C.; Child, K. J.; Tomich, E. G. Effect of particle size on blood griseofulvin-levels in man. Nature 1962, 193, 588-589.

15. Chiou, W. L.; Riegelman, S. Preparation and dissolution characteristics of several fast-release solid dispersions of griseofulvin. J. Pharm. Sci. 1969, 58, 1505-1510.

16. Chiou, W. L.; Riegelman, S. Oral absorption of griseofulvin in dogs: Increased absorption viasolid dispersion in polyethylene glycol 6000. J. Pharm. Sci. 1970, 59, 937-942.

17. Drugs@fda: Fda-approved drugs. https://www.accessdata.fda.gov/scripts/cder/daf/index.cf$\mathrm{m} ?$ event $=$ over-view.process $\& A p p l N_{0}=050475($ accessed 2021-02-21).

18. Zhong, Z.; Guo, C.; Chen, L.; Xu, J.; Huang, Y. Co-crystal formation between poly (ethylene glycol) and a small molecular drug griseofulvin. Chem. Commun. 2014, 50, 6375-6378.

19. Yang, X.; Zhong, Z.; Huang, Y. The effect of PEG molecular weights on the thermal stability and dissolution behaviors of griseofulvin-PEG crystalline inclusion complexes. Int. J. Pharm. 2016, 508, 51-60.

20. Shi, Q.; Zhang, C.; Su, Y.; Zhang, J.; Zhou, D.; Cai, T. Acceleration of crystal growth of amorphous griseofulvin by low-concentration poly(ethylene oxide): aspects of crystallization kinetics and molecular mobility. Mol. Pharmaceutics 2017, 14, 2262-2272. 
21. Malmos, G.; Wagner, A.; Maron, L. (2S,6'R)-7-chloro-2',4,6,-trimethoxy-6'-methyl-spiro(benzofuran-2(3H),2-(2')cyclohexane)-3,4'-dione $\mathrm{C}_{17} \mathrm{H}_{17} \mathrm{ClO}_{6}$. Cryst. Struct. Commun. 1977, 6, $463-470$.

22. Mahieu, A.; Willart, J. F.; Dudognon, E.; Eddleston, M. D.; Jones, W.; Danede, F.; Descamps, M. On the polymorphism of griseofulvin: identification of two additional polymorphs. J. Pharm. Sci. 2013, 102, 462-468.

23. Su, Y.; Xu, J.; Shi, Q.; Yu, L.; Cai, T. Polymorphism of griseofulvin: concomitant crystallization from the melt and a single crystal structure of a metastable polymorph with anomalously large thermal expansion. Chem. Commun. 2018, 54, 358-361.

24. Ou, X.; Li, X.; Rong, H.; Yu, L,; Lu, M. A general method for cultivating single crystals of small organic compounds from melt microdroplets. Chem. Commun. 2020, 56, 9950-9953.

25. Grove, J. F.; McGowan, J. C. Identity of griseofulvin and 'curling-factor'. Nature 1947, 160, $574-574$.

26. Chen, S.; Xi, H.; Yu, L. Cross-nucleation between ROY polymorphs. J. Am. Chem. Soc. 2005, $127,17439-17444$.

27. Desgranges, C.; Delhommelle, J. Molecular mechanism for the cross-nucleation between polymorphs. J. Am. Chem. Soc. 2006, 128, 10368-10369.

28. Yu, L. Nucleation of one polymorph by another. J. Am. Chem. Soc. 2003, 125, 6380-6381.

29. Zhong, Z.; Guo, C.; Yang, X.; Guo, B.; Xu, J.; Huang, Y. Drug molecule diflunisal forms crystalline inclusion complexes with multiple types of linear polymers. Cryst. Growth Des. 2016, $16,1181-1186$. 
30. Aitipamula, S.; Chow, P. S.; Tan, R. B. H. Solvates of the antifungal drug griseofulvin: structural, thermochemical and conformational analysis. Acta Crystallogr., Sect. B: Struct. Sci., Cryst. Eng. Mater. 2014, 70, 54-62.

31. Burger, A.; Ramberger, R. On the polymorphism of pharmaceuticals and other molecular crystals. I The theory of thermodynamic rules. Microchim. Acta. 1979, 72, 259-271.

32. Tu, W.; Knapik-Kowalczuk, J.; Chmiel, K.; Paluch, M. Glass transition dynamics and physical stability of amorphous griseofulvin in binary mixtures with low- $T_{\mathrm{g}}$ excipients. Mol. Pharmaceutics 2019, 16, 3626-3635.

33. Liu, L. Z.; Chu, B.; Penning, J. P.; St. John Manley, R. A synchrotron SAXS study of miscible blends of semicrystalline poly (vinylidenefluoride) and semicrystalline poly (1, 4-butylene adipate). II. Crystallization, morphology, and PBA inclusion in PVF2 spherulites. J. Polym. Sci. Pol. Phys. 2000, 38, 2296-2308.

34. Chen, C. H.; Lu, H. Y.; Chen, M.; Peng, J. S.; Tsai, C. J.; Yang, C. S. Synthesis and characterization of poly (ethylene succinate) and its copolyesters containing minor amounts of butylene succinate. J. Appl. Polym. Sci. 2009, 111, 1433-1439.

35. Chun, M. K.; Cho, C. S.; Choi, H. K. A novel mucoadhesive polymer prepared by template polymerization of acrylic acid in the presence of poloxamer. J. Appl. Polym. Sci. 2001, 79, 15251530.

36. Huang, C.; Powell, C. T.; Sun, Y.; Cai, T.; Yu, L. Effect of low-concentration polymers on crytal growth in molecular glasses: a controlling role for polymer segmental mobility relative to host dynamics. J. Phys. Chem. B 2017, 121, 1963-1971.

37. Brandup, J.; Immergut, E. I.; Grulke, E, A. Polymer handbook. 4th ed.; John Wiley and Sons Press: New York, 1999. 
38. Faucher, J. A.; Koleske, J. V.; Santee Jr, E. R.; Stratta, J. J.; Wilson III, C. W. Glass transition of ethylene oxide polymers. J. Appl. Phys. 1966, 37, 3962-3964.

39. Kolter, K.; Karl, M.; Gryczke, A. Hot-melt extrusion with BASF pharma polymers: extrusion compendium; BASF SE-Pharma Ingredients and Services: Germany, 2012.

40. Chen, Y.; Liu, C.; Chen, Z.; Su, C.; Hageman, M.; Hussain, M.; Haskell, R.; Stefanski, K.; Qian, F. Drug-polymer-water interaction and its implication for the dissolution performance of amorphous solid dispersions. Mol. Pharmaceutics 2015, 12, 576-589.

41. CARBOWAX ${ }^{\mathrm{TM}}$ Polyethylene Glycoles: Innovation, performance, flexibility and quality from the global leader in PEGs. The Dow Chemical Company (Dow), https://www.dow.com/content/dam/dcc/documents/en-us/catalog-selguide/118/118-01789-01-carbowax-pegs-and-mpegsselection-guide.pdf. (accessed 2021-11-05).

42. Zeng, Z.; Sun, L.; Xue, W.; Yin, N.; Zhu, W. Relationship of intrinsic viscosity to molecular weight for poly (1, 4-butylene adipate). Polym Test. 2010, 29, 66-71.

43. AquaSolve ${ }^{\mathrm{TM}}$ hydroxypropylmethylcellulose acetate succinate, physical and chemical properties handbook. Ashland, 2016. https://www.ashland.com/file_source/Ashland/Industries/Pharmaceutical/Links/PC12624.6_AquaSolve_HPMCAS_Physical_Chemical_Propertie s.pdf (accessed 2021-11-05).

44. Oh, C. M.; Heng, P. W. S.; Chan, L. W. A study on the impact of hydroxypropyl methylcellulose on the viscosity of PEG melt suspensions using surface plots and principal component analysis. AAPS. PharmSciTech. 2015, 16, 466-477.

45. Yoshioka, M.; Hancock, B. C.; Zografi, G. Crystallization of indomethacin from the amorphous state below and above its glass transition temperature. J. Pharm. Sci. 1994, 83, 17001705. 
46. Bernstein, J. Polymorphism in molecular crystals. Oxford university press: New York, 2002.

47. Steed, K. M.; Steed, J. W. Packing problems: high Z' crystal structures and their relationship to cocrystals, inclusion compounds, and polymorphism. Chem. Rev. 2015, 115, 2895-2933.

48. Sarma, B.; Roy, S.; Nangia, A. Polymorphs of 1,1-bis(4-hydroxyphenyl) cyclohexane and multiple Z' crystal structures by melt and sublimation crystallization. Chem. Commun. 2006, 49184920.

49. Li, X.; Ou, X.; Wang, B.; Rong, H.; Wang, B.; Chang, C.; Shi, B.; Yu, L.; Lu, M. Rich polymorphism in nicotinamide revealed by melt crystallization and crystal structure prediction. Commun. Chem. 2020, 3, 152-160.

50. Neumann, M. A.; van de Streek, J. How many ritonavir cases are there still out there?. Faraday Discuss. 2018, 211, 441-458.

51. Askin, S.; Cockcroft, J. K.; Price, L. S.; Gonçalves, A. D.; Zhao, M.; Tocher, D. A.; Williams, G. R.; Gaisford, S.; Craig, D. Q. M. Olanzapine form IV: Discovery of a new polymorphic form enabled by computed crystal energy landscapes. Cryst. Growth Des. 2019, 19, 2751-2757.

52. Skomski, D.; Varsolona, R. J.; Su, Y.; Zhang, J.; Teller, R.; Forster, S. P.; Barrett, S. E.; Xu, W. Islatravir case study for enhanced screening of thermodynamically stable crystalline anhydrate phases in pharmaceutical process development by hot melt extrusion. Mol. Pharmaceutics 2020, $17,2874-2881$. 


\section{Table of Contents}

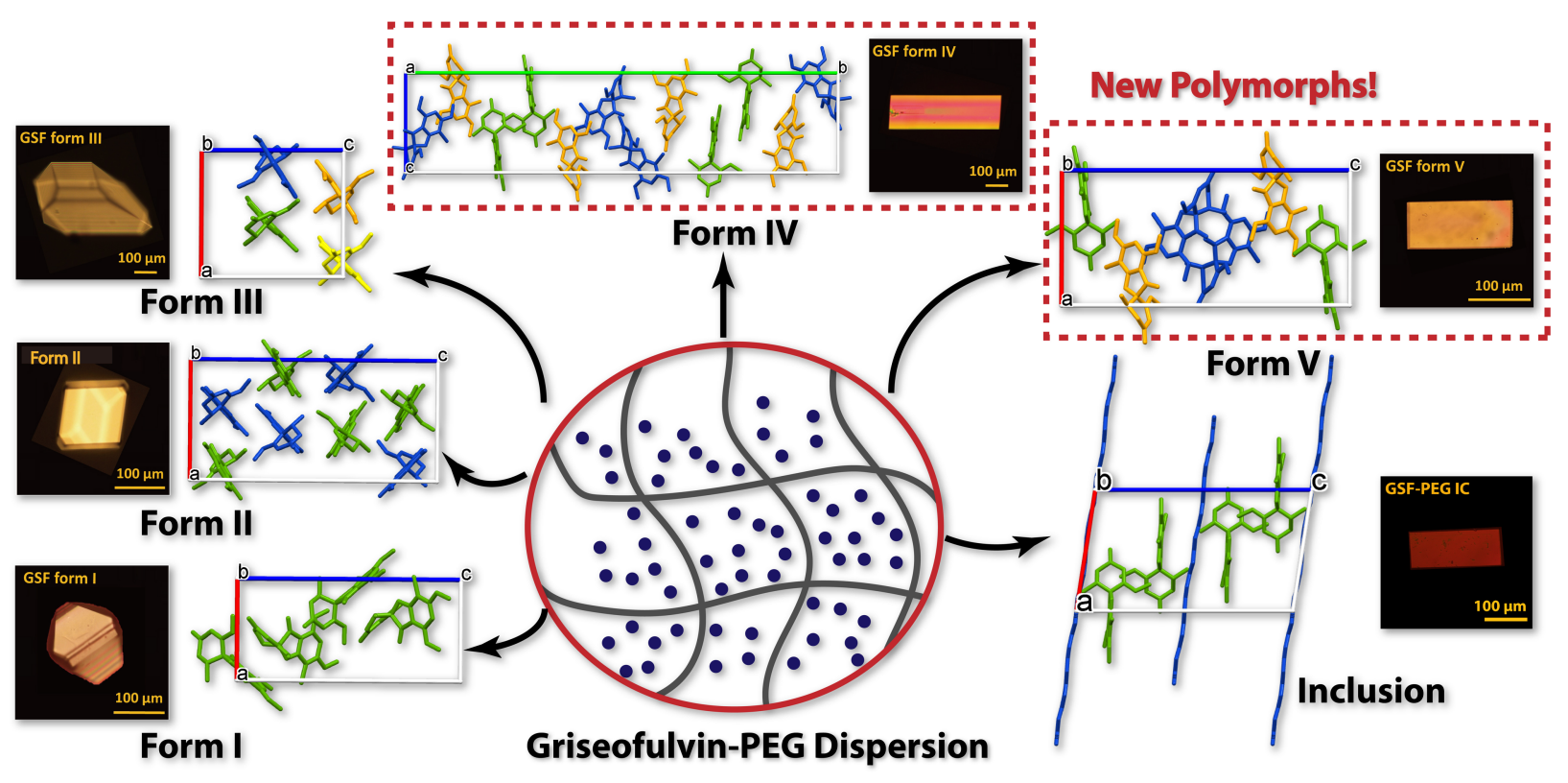

